Article

\title{
Stress-Rupture of Fiber-Reinforced Ceramic-Matrix Composites with Stochastic Loading at Intermediate Temperatures. Part I: Theoretical Analysis
}

\author{
Longbiao Li $\mathbb{D}$ \\ College of Civil Aviation, Nanjing University of Aeronautics and Astronautics, Nanjing 210016, China; \\ 1lb451@nuaa.edu.cn; Tel.: +86-25-84895963
}

Received: 31 August 2019; Accepted: 23 September 2019; Published: 25 September 2019

\begin{abstract}
Under stress-rupture loading, stochastic loading affects the internal damage evolution and lifetime of fiber-reinforced ceramic-matrix composites (CMCs) at intermediate temperatures. The damage mechanisms of the matrix cracking, fiber/matrix interface debonding and oxidation, and fiber fracture are considered in the analysis of stochastic loading. The strain, fiber/matrix interface debonding and oxidation length, and the broken fibers fraction versus the time curves of $\mathrm{SiC} / \mathrm{SiC}$ composite under constant and three different stochastic loading conditions are analyzed. The effects of the stochastic loading stress level, stochastic loading time, and time spacing on the damage evolution and lifetime of $\mathrm{SiC} / \mathrm{SiC}$ composite are discussed. When the stochastic loading stress level increases, the stress-rupture lifetime decreases, and the time for the interface complete debonding and oxidation decreases. When the stochastic loading time and time spacing increase, the stress-rupture lifetime decreases, and the time for the interface complete debonding and oxidation remains the same.
\end{abstract}

Keywords: ceramic-matrix composites (CMCs); stress-rupture; stochastic loading; matrix cracking; interface debonding; fiber failure; lifetime

\section{Introduction}

Ceramic-matrix composites (CMCs) are a new type of thermal-structural-functional integrated material with the advantages of metal materials, ceramic materials, and carbon materials [1]. They have the characteristics of material-structural integration. Through the optimization design of each structural unit, synergistic effects can be produced, and high performance and reasonable matching of each performance can be achieved. Therefore, CMCs have high temperature resistance, corrosion resistance, wear resistance, low density, high specific strength, high specific modulus, low thermal expansion coefficient, insensitivity to cracks, no catastrophic damage, and other advantages [2]. Compared to metallic alloys, CMCs can have a density reduction of 30-50\% and can exceed the working temperature range [3]. With the increase of thrust-weight ratio and turbine inlet temperature, CMCs have become one of the preferred high-temperature structural materials for aeroengines. When CMCs are used in hot-section components in aeroengines, i.e., turbine, combustion chamber, combustion liner, and nozzles, the amount of cooling air can be significantly reduced or even zero, the combustion efficiency can be improved, and the pollution emission and noise level can be reduced. At present, the application of CMCs in aeroengines follows the development idea from stationary parts to rotating parts, from intermediate temperature parts (i.e., $700-1000{ }^{\circ} \mathrm{C}$ ) to high temperature parts (i.e., $1000-1300^{\circ} \mathrm{C}$ ), and gives priority to developing intermediate temperature and intermediate load (i.e., less than $120 \mathrm{MPa}$ ) stationary parts (i.e., seals and flaps, etc.), then the high temperature intermediate load (i.e., less than $120 \mathrm{MPa}$ ) stationary parts (i.e., flame tube, flame holder, turbine outer ring, guide vane, etc.), and then the high temperature and high load (i.e., higher than $120 \mathrm{MPa}$ ) rotating parts (i.e., turbine rotor, turbine 
blade, etc.). The CMC nozzle flaps, and seals have already been applied in M53-2, M88, M88-2, F100, F119, EJ200, F414, F110, and F136 aeroengines [4].

Since the applications for fiber-reinforced CMCs involve components with lives that are measured in tens of thousands of hours, the successful design and implementation of CMC components depend on the knowledge of the material behavior over periods of time comparable to the expected service life of the component [5]. In order to ensure the reliability and safety of fiber-reinforced CMCs hot-section components used in aeroengines, it is necessary to develop performance evaluation, damage evolution, and strength and life prediction tools or models [6-8]. Under constant stress loading at intermediate temperatures, multiple damage mechanisms of matrix cracking, fiber/matrix interface debonding, and interphase and fiber oxidation occurs in CMCs [9-11]. Hussain et al. [12] and Khosravani et al. [13] performed investigations on the thermal issues on composites. Morscher et al. [14] investigated the stress-rupture of a woven $\mathrm{SiC} / \mathrm{SiC}$ composite with the $\mathrm{BN}$ interphase. Two regimes exist in the stress-rupture lifetime curve, i.e., a high-stress regime where rupture occurs at a fast rate and a low-stress regime where rupture occurs at a slower rate. Morscher and Cawley [15] investigated the time-dependent strength degradation of $\mathrm{SiC} / \mathrm{SiC}$ composite at intermediate temperature. $\mathrm{Li}[16,17]$ investigated the damage evolution of cross-ply CMCs under stress-rupture and cyclic loading at elevated temperature. Momon et al. [18] and Godin et al. [19] investigated the stress-rupture lifetime of $\mathrm{SiC} / \mathrm{SiC}$ composite using acoustic emission analysis. Ikarashi et al. [20] investigated the effect of cyclic tensile loading on the rupture behavior of orthogonal three-dimensional (3D) SiC/SiC composite at elevated temperature in air atmosphere. The matrix cracking propagation caused by the oxidation of the fiber/matrix interface and the degradation of the interfacial shear stress affects the lifetime of $\mathrm{SiC} / \mathrm{SiC}$ composite. However, the effect of stochastic loading on the damage evolution and lifetime of CMCs has not been investigated.

The objective of this paper was to investigate the damage evolution and lifetime of fiber-reinforced CMCs under stress-rupture with stochastic loading at intermediate temperatures. Four different loading cases, including constant loading and stochastic loading with different stress levels, time, and time spacing, were considered in the analysis. The relationships between the stochastic loading stress, time and time spacing, the fiber/matrix interface debonding, broken fiber fraction, and lifetime of fiber-reinforced CMCs were established. The evolution of the strain, the fiber/matrix interface debonding and oxidation length, the broken fiber fraction, and the lifetime of $\mathrm{SiC} / \mathrm{SiC}$ composite at $800^{\circ} \mathrm{C}$ in air atmosphere was analyzed.

\section{Theoretical model}

When stochastic loading occurs during constant stress loading at an elevated temperature, the damage extent inside of fiber-reinforced CMCs becomes much more serious. In the present analysis, the shear-lag model was used to analyze the stress distribution of damaged CMCs under stress-rupture with stochastic loading. The damage mechanisms of the matrix cracking, fiber/matrix interface debonding and oxidation, and broken fibers were considered. The matrix stochastic cracking model, fracture mechanics approach, and Global Load Sharing criterion were used to determine the matrix crack spacing, fiber/matrix interface debonding length, and the broken fibers fraction under stress-rupture with stochastic loading. The constitutive relationship considering the time-dependent damage mechanisms was also developed.

Figure 1 shows the stochasic loading sequence under constant stress-rupture laoding of fiber-reinforced CMCs at an elevated temperatrue, which can be divided into four cases, as follows:

(1) Case I, constant stress loading;

(2) Case II, constant stress loading and stochsatic loading of $\sigma_{\mathrm{a}}$ with $\Delta t_{\mathrm{a}}$;

(3) Case III, constant stress loading and stochastic loading of $\sigma_{\mathrm{a}}$ and $\sigma_{\mathrm{b}}$ with $\Delta t_{\mathrm{a}}$ and $\Delta t_{\mathrm{b}}$;

(4) Case IV, constant stress loading and stochastic loading of $\sigma_{\mathrm{a}}, \sigma_{\mathrm{b}}$ and $\sigma_{\mathrm{c}}$ with $\Delta t_{\mathrm{a}}, \Delta t_{\mathrm{b}}$, and $\Delta t_{\mathrm{c}}$. 


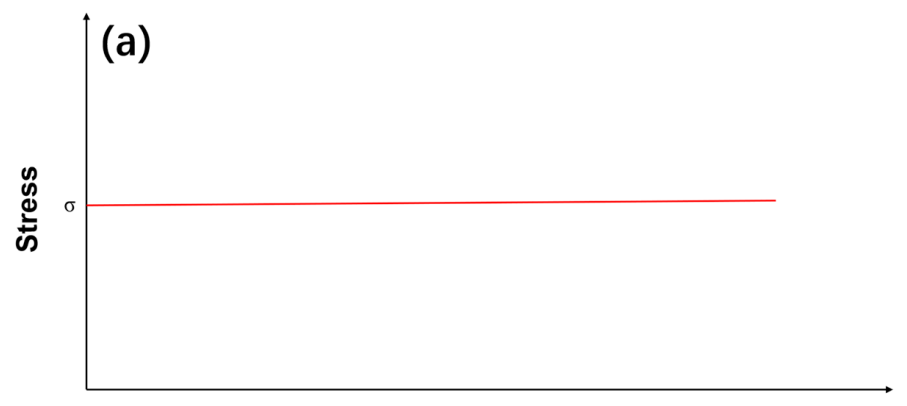

Time
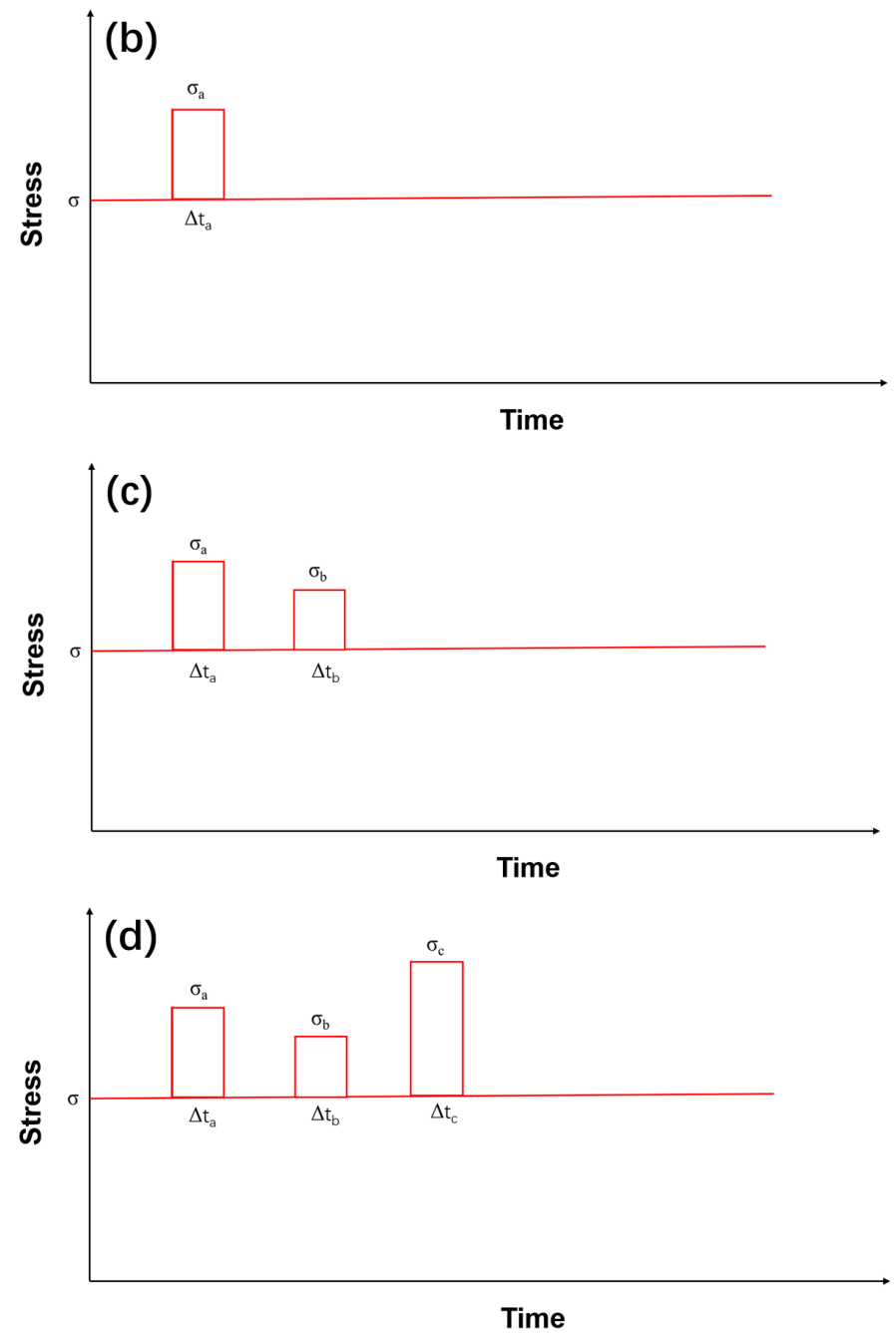

Figure 1. The schematic of loading sequence of (a) constant loading; (b) stochastic loading of $\sigma_{\mathrm{a}}$ and $\Delta t_{\mathrm{a}}$; (c) stochastic loading of $\sigma_{\mathrm{a}}, \sigma_{\mathrm{b}}$ and $\Delta t_{\mathrm{a}}, \Delta t_{\mathrm{b}}$; and (d) stochastic loading of $\sigma_{\mathrm{a}}, \sigma_{\mathrm{b}}, \sigma_{\mathrm{c}}$ and $\Delta t_{\mathrm{a}}, \Delta t_{\mathrm{b}}, \Delta t_{\mathrm{c}}$.

Figure 2 shows a unit cell used for the stress analysis of the fiber and the matrix when the matrix cracking, fiber/matrix interface debonding, and fiber failure appear inside of CMCs. When the fiber fractures under stochastic loading, the fiber axial stress distribution can be determined using the following equation:

$$
\sigma_{\mathrm{f}}(x, t)=\left\{\begin{array}{l}
T_{S}(t)-\frac{2 \tau_{\mathrm{f}}}{r_{\mathrm{f}}} x, x \in[0, \zeta(t)] \\
T_{S}(t)-\frac{2 \tau_{\mathrm{f}}}{r_{\mathrm{f}}} \zeta(t)-\frac{2 \tau_{\mathrm{i}}}{r_{\mathrm{f}}}(x-\zeta(t)), x \in\left[\zeta(t), l_{\mathrm{d}}(t)\right] \\
\sigma_{\mathrm{fo}}+\left[T_{S}(t)-\sigma_{\mathrm{fo}}-\frac{2 \tau_{\mathrm{f}}}{r_{\mathrm{f}}} \zeta(t)-\frac{2 \tau_{\mathrm{i}}}{r_{\mathrm{f}}}\left(l_{\mathrm{d}}(t)-\zeta(t)\right)\right] \exp \left(-\rho \frac{x-l_{\mathrm{d}}(t)}{r_{\mathrm{f}}}\right), x \in\left[l_{\mathrm{d}}(t), \frac{l_{\mathrm{c}}}{2}\right]
\end{array}\right.
$$


where $r_{\mathrm{f}}$ denotes the fiber radius; $\tau_{\mathrm{f}}$ denotes the fiber/matrix interface shear stress in the oxidation region; $\tau_{\mathrm{i}}$ denotes the fiber/matrix interface shear stress in the slip region; $T_{S}(t)$ denotes the intact fiber stress under stochastic loading; $l_{\mathrm{d}}(t)$ denotes the time-dependent fiber/matrix interface debonding length under stochastic loading; $l_{c}$ denotes the matrix crack spacing under stochastic loading; $\rho$ denotes the shear-lag model parameter; and $\zeta(t)$ denotes the time-dependent fiber/matrix interface oxidation length [21].

$$
\zeta(t)=\varphi_{1}\left[1-\exp \left(-\frac{\varphi_{2} t}{b}\right)\right]
$$

where $b$ is a delay factor considering the deceleration of reduced oxygen activity, and $\varphi_{1}$ and $\varphi_{2}$ are parameters dependent on temperature and described using the Arrhenius type laws. The fiber axial stress in the fiber/matrix interface bonded region can be determined using the following equation:

$$
\sigma_{\mathrm{fo}}=\frac{E_{\mathrm{f}}}{E_{\mathrm{c}}} \sigma+E_{\mathrm{f}}\left(\alpha_{\mathrm{c}}-\alpha_{\mathrm{f}}\right) \Delta \mathrm{T}
$$

where $E_{\mathrm{f}}$, and $E_{\mathrm{c}}$ denote the fiber and the composite elastic modulus, respectively; $\alpha_{\mathrm{f}}$, and $\alpha_{\mathrm{c}}$ denote the fiber and the composite thermal expansion coefficient, respectively; and $\Delta \mathrm{T}$ denotes the temepratrue difference between the testing temperature and the fabrication temperatrue.

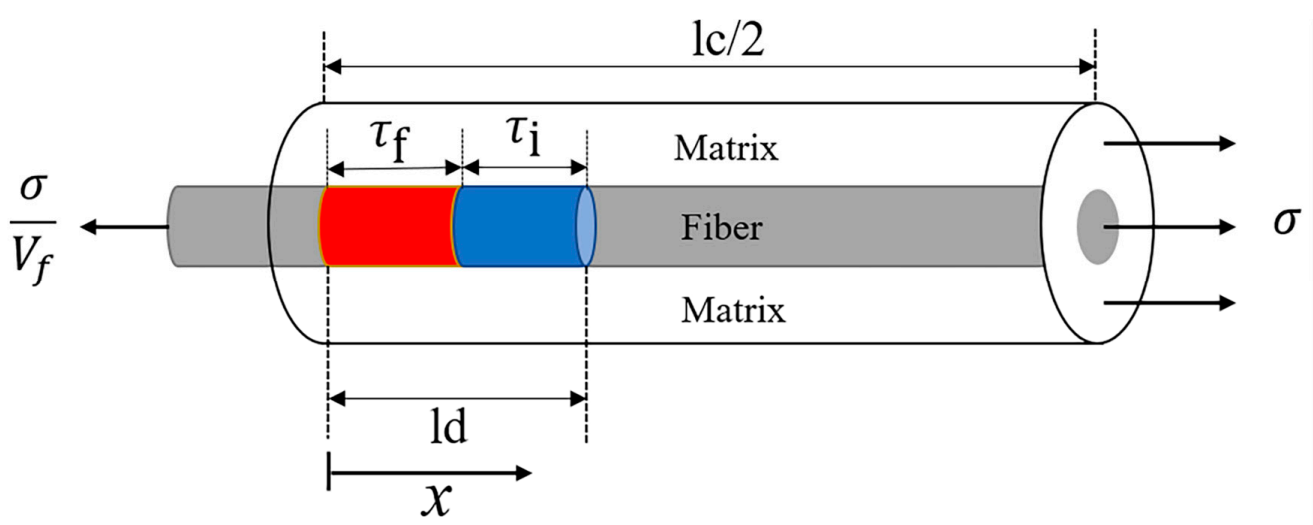

Figure 2. The unit cell of the shear-lag model.

The matrix cracking under stochastic loading can be described using the two-parameter Weibull distribution, and the time-dependent matrix crack spacing under stochastic loading can be determined using the following equation [22]:

$$
l_{\mathrm{c}}=r_{\mathrm{f}} \frac{V_{\mathrm{m}} E_{\mathrm{m}}}{V_{\mathrm{f}} E_{\mathrm{c}}} \frac{\sigma_{\mathrm{R}}}{2 \tau_{\mathrm{i}}} \Lambda\left\{1-\exp \left[-\left(\frac{\sigma_{S}-\left(\sigma_{\mathrm{mc}}-\sigma_{\mathrm{th}}\right)}{\left(\sigma_{\mathrm{R}}-\sigma_{\mathrm{th}}\right)-\left(\sigma_{\mathrm{mc}}-\sigma_{\mathrm{th}}\right)}\right)^{m}\right]\right\}^{-1}
$$

where $\sigma_{S}$ denotes the stochastic loading stress; $E_{\mathrm{m}}$ denotes the matrix elastic modulus; $\sigma_{\mathrm{R}}$ denotes the matrix cracking characteristic strength; $\sigma_{\mathrm{mc}}$ denotes matrix first cracking stress; $\sigma_{\mathrm{th}}$ denotes matrix thermal residual stress; $\Lambda$ denotes the final nominal crack space; and $m$ denotes matrix Weibull modulus.

The time-dependent fiber/matrix interface debonding length under stochastic loading can be determined using the fracture mechanics approach [23]:

$$
\xi_{\mathrm{d}}=-\frac{F}{4 \pi r_{\mathrm{f}}} \frac{\partial w_{\mathrm{f}}\left(\sigma_{S}, t\right)}{\partial l_{\mathrm{d}}}-\frac{1}{2} \int_{0}^{l_{\mathrm{d}}} \tau_{\mathrm{i}} \frac{\partial v\left(\sigma_{S}, t\right)}{\partial l_{\mathrm{d}}} d x
$$

where $\xi_{\mathrm{d}}$ denotes the fiber/matrix interface debonding energy; $F\left(=\pi r_{\mathrm{f}}^{2} \sigma / V_{\mathrm{f}}\right)$ denotes the fiber stress at the matrix cracking plane; $w_{\mathrm{f}}\left(\sigma_{S}, t\right)$ denotes the time-dependent fiber axial displacement under stochastic loading at the matrix cracking plane; and $v\left(\sigma_{S}, t\right)$ denotes the time-dependent relative displacement between the fiber and the matrix under stochastic loading. Substituting the time-dependent fiber axial 
displacement and relative displacement into Equation (5), the time-dependent fiber/matrix interface debonding length under stochastic loading can be determined using the following equation:

$$
l_{\mathrm{d}}\left(\sigma_{S}, t\right)=(1-\eta) \zeta(t)+\frac{r_{\mathrm{f}}}{2}\left(\frac{V_{\mathrm{m}} E_{\mathrm{m}} T_{S}}{E_{\mathrm{c}} \tau_{\mathrm{i}}}-\frac{1}{\rho}\right)-\sqrt{\left(\frac{r_{\mathrm{f}}}{2 \rho}\right)^{2}-\frac{r_{\mathrm{f}}^{2} V_{\mathrm{f}} V_{\mathrm{m}} E_{\mathrm{f}} E_{\mathrm{m}} T_{S}^{2}}{4 E_{\mathrm{c}}^{2} \tau_{\mathrm{i}}^{2}}\left(1-\frac{\sigma}{V_{\mathrm{f}} T_{S}}\right)+\frac{r_{\mathrm{f}} V_{\mathrm{m}} E_{\mathrm{f}} E_{\mathrm{m}}}{E_{c} \tau_{\mathrm{i}}^{2}} \xi_{\mathrm{d}}}
$$

where $\eta=\tau_{\mathrm{f}} / \tau_{\mathrm{i}}$.

The two-parameter Weibull model was adopted to describe the fiber strength distribution, and the Global Load Sharing criterion was used to determine the stress distributions between the intact and fracture fibers [24].

$$
\frac{\sigma}{V_{\mathrm{f}}}=T_{S}\left(1-P\left(T_{S}\right)\right)+\frac{2 \tau_{\mathrm{f}}}{r_{\mathrm{f}}}\langle L\rangle P\left(T_{S}\right)
$$

where $\langle L\rangle$ denotes the average fiber pullout length, and $P\left(T_{S}\right)$ denotes the fiber failure probability.

$$
P\left(T_{S}\right)=1-\exp \left[-\left(\frac{T_{S}}{\sigma_{\mathrm{c}}}\right)^{m_{\mathrm{f}}+1}\right]
$$

where $m_{\mathrm{f}}$ denotes the fiber Weibull modulus, and $\sigma_{\mathrm{c}}$ denotes the fiber characteristic strength of a length $\delta_{\mathrm{c}}$ of fiber.

$$
\sigma_{\mathrm{c}}=\left(\frac{l_{\mathrm{o}} \sigma_{0}^{m_{\mathrm{f}}}(t) \tau_{\mathrm{i}}}{r_{\mathrm{f}}}\right)^{\frac{1}{m_{\mathrm{f}}+1}}, \delta_{\mathrm{c}}=\left(\frac{\sigma_{0}(t) r_{\mathrm{f}} \mathrm{o}_{\mathrm{o}}^{\frac{1}{m_{\mathrm{f}}}}}{\tau_{\mathrm{i}}}\right)^{\frac{m_{\mathrm{f}}}{m_{\mathrm{f}}+1}}
$$

where [25].

$$
\sigma_{0}(t)=\left\{\begin{array}{l}
\sigma_{0}, t \leq \frac{1}{k}\left(\frac{K_{\mathrm{IC}}}{Y \sigma_{0}}\right)^{4} \\
\frac{K_{\mathrm{IC}}}{Y \sqrt[4]{k t}}, t>\frac{1}{k}\left(\frac{K_{\mathrm{IC}}}{Y \sigma_{0}}\right)^{4}
\end{array}\right.
$$

where $\sigma_{0}$ denotes the time-dependent fiber strength; $K_{\text {IC }}$ denotes the fracture toughness; $Y$ denotes the geometric parameter; and $k$ is the parabolic rate constant.

When multiple damage mechanisms form inside of fiber-reinforced CMCs, the average composite strain of $\varepsilon_{\mathrm{c}}(t)$ can be determined by integration of the axial strain in the fiber.

$$
\varepsilon_{\mathrm{c}}\left(\sigma_{S}, t\right)=\frac{2}{E_{\mathrm{f}} l_{\mathrm{c}}} \int_{l_{\mathrm{c}} / 2} \sigma_{\mathrm{f}}(x, t) d x-\left(\alpha_{\mathrm{c}}-\alpha_{\mathrm{f}}\right) \Delta \mathrm{T}
$$

Substituting the time-dependent fiber axial stress under stochastic loading in Equation (1) into Equation (11), the composite average strain of $\varepsilon_{\mathrm{c}}\left(\sigma_{S}, t\right)$ can be determined using the following equation:

$$
\varepsilon_{\mathrm{c}}\left(\sigma_{S}, t\right)=\left\{\begin{array}{l}
\frac{T_{S}(t)}{E_{\mathrm{f}}} \frac{2 l_{\mathrm{d}}(t)}{l_{\mathrm{c}}}+\frac{2 \tau_{\mathrm{f}}}{r_{\mathrm{f}} \mathrm{f}_{\mathrm{f}} l_{\mathrm{c}}} \zeta^{2}(t)-\frac{4 \tau_{\mathrm{f}} l_{\mathrm{d}}(t)}{r_{\mathrm{f}} E_{\mathrm{f}} l_{\mathrm{c}}} \zeta(t)-\frac{2 \tau_{\mathrm{i}}}{r_{\mathrm{f}} E_{\mathrm{f}} l_{\mathrm{c}}}\left(l_{\mathrm{d}}(t)-\zeta(t)\right)^{2}+\frac{2 \sigma_{\mathrm{fo}}}{E_{\mathrm{f}} l_{\mathrm{c}}}\left(\frac{l_{\mathrm{c}}}{2}-l_{\mathrm{d}}(t)\right) \\
\left.+\frac{2 r_{\mathrm{f}}}{\rho E_{\mathrm{f}} l_{\mathrm{c}}}\left\{T_{S}(t)-\frac{2 \tau_{\mathrm{f}}}{r_{\mathrm{f}}} \zeta(t)-\frac{2 \tau_{i}}{r_{\mathrm{f}}} l_{\mathrm{d}}(t)-\zeta(t)\right]-\sigma_{\mathrm{fo}}\right\} \\
\times\left[1-\exp \left(-\rho \frac{l_{\mathrm{c}} / 2-l_{\mathrm{d}}(t)}{r_{\mathrm{f}}}\right)\right]-\left(\alpha_{\mathrm{c}}-\alpha_{\mathrm{f}}\right) \Delta \mathrm{T}, l_{\mathrm{d}}(t)<\frac{l_{\mathrm{c}}}{2} \\
\quad \times\left[\frac{T_{S}(t)}{E_{\mathrm{f}}} \frac{2 l_{\mathrm{d}}(t)}{l_{\mathrm{c}}}+\frac{2 \tau_{\mathrm{f}}}{r_{\mathrm{f}} E_{\mathrm{f}} l_{\mathrm{c}}} \zeta^{2}(t)-\frac{4 \tau_{\mathrm{f}} l_{\mathrm{d}}(t)}{r_{\mathrm{f}} E_{\mathrm{f}} l_{\mathrm{c}}} \zeta(t)-\frac{2 \tau_{\mathrm{i}}}{r_{\mathrm{f}} E_{\mathrm{f}} l_{\mathrm{c}}}\left(l_{\mathrm{d}}(t)-\zeta(t)\right)^{2}, l_{d}(t)=\frac{l_{\mathrm{c}}}{2}\right.
\end{array}\right.
$$

\section{Results and analysis}

The strain, fiber/matrix interface debonding and oxidation length, and broken fibers fraction versus the time curves of $\mathrm{SiC} / \mathrm{SiC}$ composite were analyzed for the Cases II, III, and IV. The material properties were given by: $V_{\mathrm{f}}=20 \%, E_{\mathrm{f}}=270 \mathrm{GPa}, E_{\mathrm{m}}=400 \mathrm{GPa}, r_{\mathrm{f}}=7 \mu \mathrm{m}, m=3, \alpha_{\mathrm{f}}=3.5 \times 10^{-6} /{ }^{\circ} \mathrm{C}$, $\alpha_{\mathrm{m}}=4.6 \times 10^{-6} /{ }^{\circ} \mathrm{C}, \Delta \mathrm{T}=-1000{ }^{\circ} \mathrm{C}, \xi_{\mathrm{d}}=0.1 \mathrm{~J} / \mathrm{m}^{2}, \tau_{\mathrm{i}}=30 \mathrm{MPa}, \tau_{\mathrm{f}}=1 \mathrm{MPa}, \sigma_{0}=2.5 \mathrm{GPa}, l_{0}=25 \mathrm{~mm}$, $m_{\mathrm{f}}=5$, and Tem $=800^{\circ} \mathrm{C}$. 


\subsection{Case II}

For the stochastic loading of Case II, the strain, interface debonding and oxidation length, and the broken fibers fraction of $\mathrm{SiC} / \mathrm{SiC}$ composite under stress-rupture loading of constant stress of $\sigma=120$ $\mathrm{MPa}, \sigma_{\mathrm{S}}=140,160$, and $180 \mathrm{MPa}$ at $t=36 \mathrm{kseconds}$ and $\Delta t=36 \mathrm{kseconds}$ at $800{ }^{\circ} \mathrm{C}$ in air atmosphere are shown in Figure 3 and Table 1 . When the stochastic loading stress level increases, the stress-rupture lifetime decreases, and the time for the interface complete debonding and oxidation decreases.
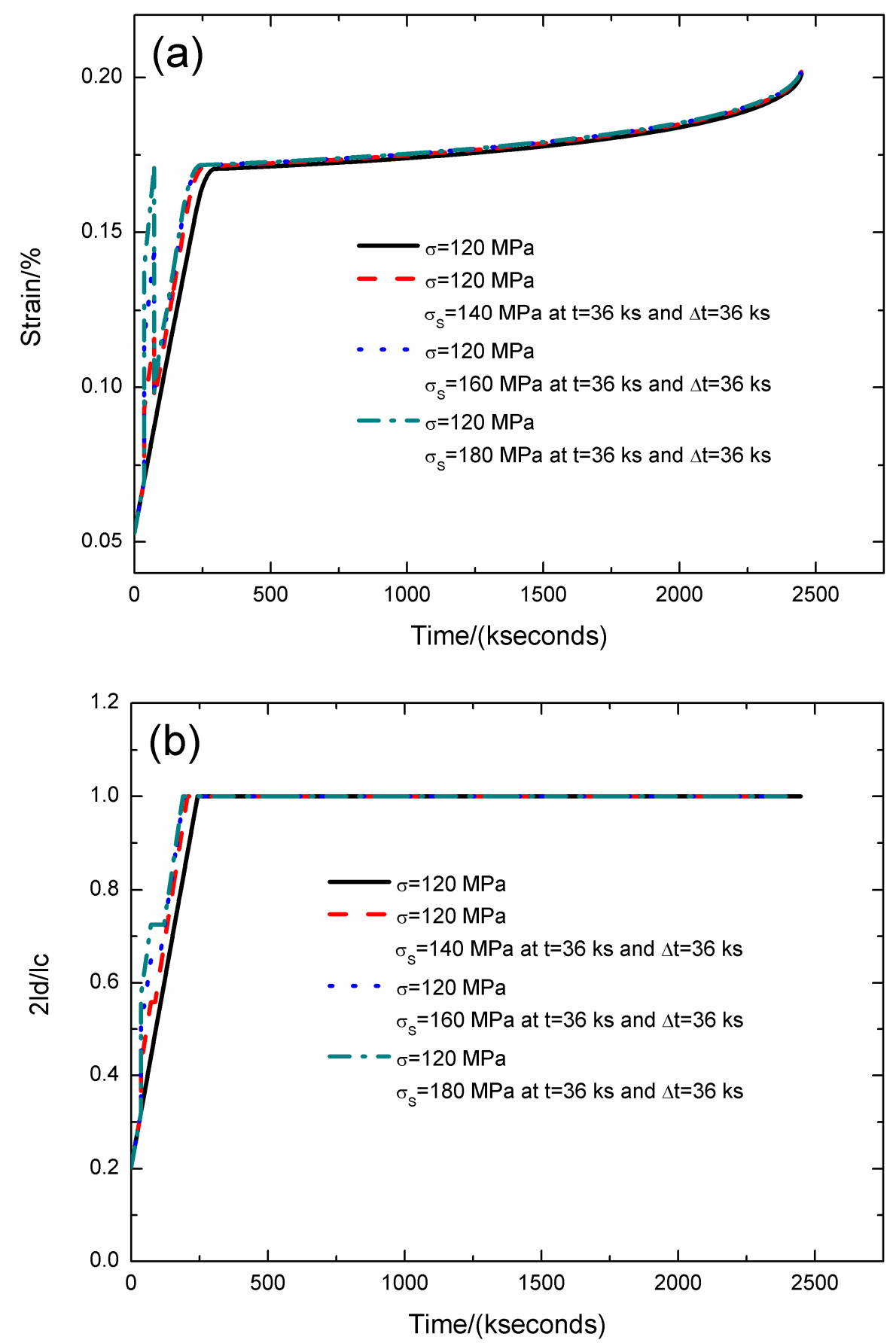

Figure 3. Cont. 

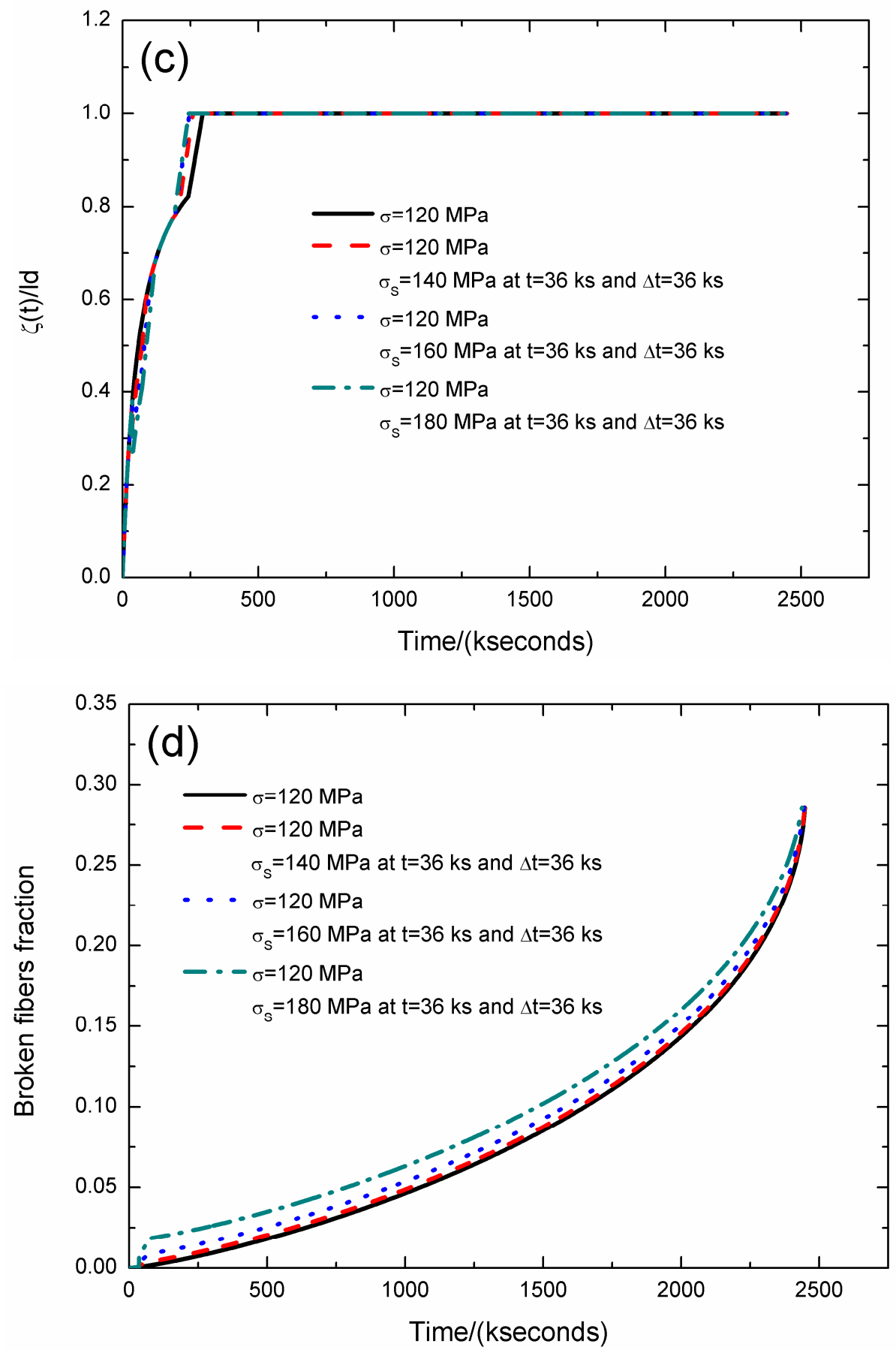

Figure 3. (a) The strain versus the time curves; (b) the fiber/matrix interface debonding length versus the time curves; (c) the fiber/matrix interface oxidation length versus the time curves; and (d) the broken fibers fraction versus the time curves of $\mathrm{SiC} / \mathrm{SiC}$ composite under stress-rupture loading of constant stress of $\sigma=120 \mathrm{MPa}, \sigma_{\mathrm{S}}=140,160,180 \mathrm{MPa}$ at $t=36 \mathrm{kseconds}$ and $\Delta \mathrm{t}=36 \mathrm{kseconds}$ at $800{ }^{\circ} \mathrm{C}$ in air atmosphere. 
Table 1. The strain, fiber/matrix interface debonding and oxidation length, and broken fibers fraction of $\mathrm{SiC} / \mathrm{SiC}$ composite under stress-rupture loading of constant stress of $\sigma=120 \mathrm{MPa}, \sigma_{\mathrm{S}}=140,160,180$ $\mathrm{MPa}$ at $t=36 \mathrm{kseconds}$ and $\Delta \mathrm{t}=36 \mathrm{kseconds}$ at $800^{\circ} \mathrm{C}$ in air atmosphere.

\begin{tabular}{ccccccccc}
\hline$\sigma / \mathrm{MPa}$ & $\mathbf{1 2 0}$ & $\mathbf{1 2 0}$ & $\mathbf{1 2 0}$ & $\mathbf{1 2 0}$ & $\mathbf{1 2 0}$ & & & \\
\hline$t / \mathrm{kseconds}$ & 0 & 36 & 242.7 & 295.3 & 2447.9 & & & \\
\hline$\varepsilon_{\mathrm{c}} / \%$ & 0.053 & 0.07 & 0.163 & 0.17 & 0.201 & & & \\
$2 l_{\mathrm{d}} / l_{\mathrm{c}}$ & 0.203 & 0.322 & 1.0 & 1.0 & 1.0 & & & \\
$\zeta / l_{\mathrm{d}}$ & 0 & 0.380 & 0.822 & 1.0 & 1.0 & & & \\
$P$ & $1 \times 10^{-6}$ & $6.5 \times 10^{-4}$ & 0.007 & 0.009 & 0.285 & & & 120 \\
\hline$\sigma / \mathrm{MPa}$ & 120 & 120 & 140 & 140 & 120 & 120 & 120 & 2546.9 \\
$t / \mathrm{kseconds}$ & 0 & 36 & 36 & 72 & 72 & 205.7 & 259.4 & 202 \\
\hline$\varepsilon_{\mathrm{c}} / \%$ & 0.053 & 0.07 & 0.093 & 0.115 & 0.096 & 0.162 & 0.171 & 0.20 \\
$2 l_{\mathrm{d}} / l_{\mathrm{c}}$ & 0.203 & 0.322 & 0.423 & 0.558 & 0.558 & 1.0 & 1.0 & 1.0 \\
$\zeta / l_{\mathrm{d}}$ & 0 & 0.380 & 0.328 & 0.498 & 0.498 & 0.794 & 1.0 & 1.0 \\
$P$ & $1 \times 10^{-6}$ & $6.5 \times 10^{-4}$ & 0.001 & 0.004 & 0.004 & 0.008 & 0.01 & 0.285 \\
\hline$\sigma / \mathrm{MPa}$ & 120 & 120 & 160 & 160 & 120 & 120 & 200 & 200 \\
$t / \mathrm{kseconds}$ & 0 & 36 & 36 & 72 & 72 & 192.6 & 246.8 & 2444.3 \\
\hline$\varepsilon_{\mathrm{c}} / \%$ & 0.053 & 0.07 & 0.116 & 0.143 & 0.099 & 0.162 & 0.171 & 0.201 \\
$2 l_{\mathrm{d}} / l_{\mathrm{c}}$ & 0.203 & 0.322 & 0.506 & 0.649 & 0.649 & 1.0 & 1.0 & 1.0 \\
$\zeta / l_{\mathrm{d}}$ & 0 & 0.380 & 0.289 & 0.45 & 0.45 & 0.781 & 1.0 & 1.0 \\
$P$ & $1 \times 10^{-6}$ & $6.5 \times 10^{-4}$ & 0.003 & 0.008 & 0.008 & 0.012 & 0.014 & 0.285 \\
\hline$\sigma / \mathrm{MPa}$ & 120 & 120 & 180 & 180 & 120 & 120 & 120 & 120 \\
$t / \mathrm{kseconds}$ & 0 & 36 & 36 & 72 & 72 & 189.1 & 243.1 & 2437 \\
\hline$\varepsilon_{\mathrm{c}} / \%$ & 0.053 & 0.07 & 0.138 & 0.17 & 0.098 & 0.162 & 0.171 & 0.2 \\
$2 l_{\mathrm{d}} / l_{\mathrm{c}}$ & 0.203 & 0.322 & 0.578 & 0.724 & 0.724 & 1.0 & 1.0 & 1.0 \\
$\zeta / l_{\mathrm{d}}$ & 0 & 0.380 & 0.257 & 0.409 & 0.409 & 0.778 & 1.0 & 1.0 \\
$P$ & $1 \times 10^{-6}$ & $6.5 \times 10^{-4}$ & 0.007 & 0.018 & 0.018 & 0.022 & 0.024 & 0.285 \\
\hline
\end{tabular}

Under constant stress loading of $\sigma=120 \mathrm{MPa}$, the stress-rupture lifetime is $t=2447.9 \mathrm{kseconds}$; the time for the interface complete debonding is $t=242.7 \mathrm{kseconds}$; the time for the interface complete oxidation is $t=295.3$ kseconds; the failure strain is $\varepsilon_{\mathrm{C}}=0.201 \%$; and the broken fibers fraction is $P=0.285$. When the stochastic loading stress is $\sigma_{\mathrm{S}}=140 \mathrm{MPa}$, the stress-rupture lifetime is $t=2446.9$ kseconds; the time for the interface complete debonding is $t=205.7 \mathrm{kseconds}$; the time for the interface complete oxidation is $t=259.4$ kseconds; the failure strain is $\varepsilon_{\mathrm{C}}=0.202 \%$; and the broken fibers fraction is $P=0.285$. When the stochastic loading stress is $\sigma_{S}=160 \mathrm{MPa}$, the stress-rupture lifetime is $t=2444.3$ kseconds; the time for the interface complete debonding is $t=192.6 \mathrm{kseconds}$; the time for the interface complete oxidation is $t=246.8$ kseconds; the failure strain is $\varepsilon_{\mathrm{C}}=0.201 \%$; and the broken fibers fraction is $P=0.285$. When the stochastic loading stress is $\sigma_{S}=180 \mathrm{MPa}$, the stress-rupture lifetime is $t=2437$ kseconds; the time for the interface complete debonding is $t=189.1$ kseconds; the time for the interface complete oxidation is $t=243.1$ kseconds; the failure strain is $\varepsilon_{\mathrm{c}}=0.2 \%$; and the broken fibers fraction is $P=0.285$.

The strain, interface debonding and oxidation length, and the broken fibers fraction of $\mathrm{SiC} / \mathrm{SiC}$ composite under stress-rupture loading of constant stress of $\sigma=120 \mathrm{MPa}, \sigma_{\mathrm{S}}=140 \mathrm{MPa}$ at $t=72,108$, 144 kseconds and $\Delta t=36$ kseconds at $800{ }^{\circ} \mathrm{C}$ in air atmosphere are shown in Figure 4 and Table 2. 

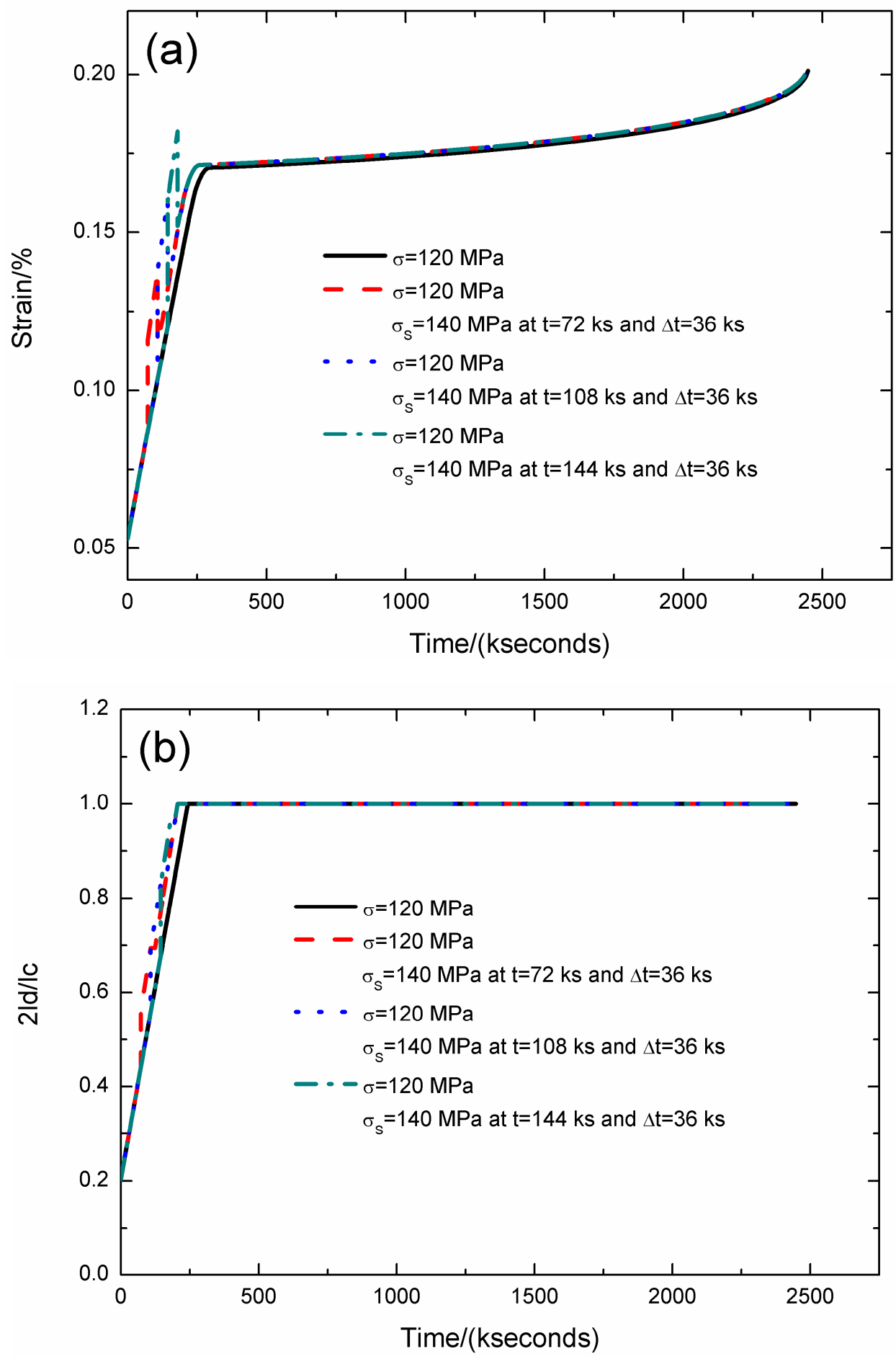

Figure 4. Cont. 

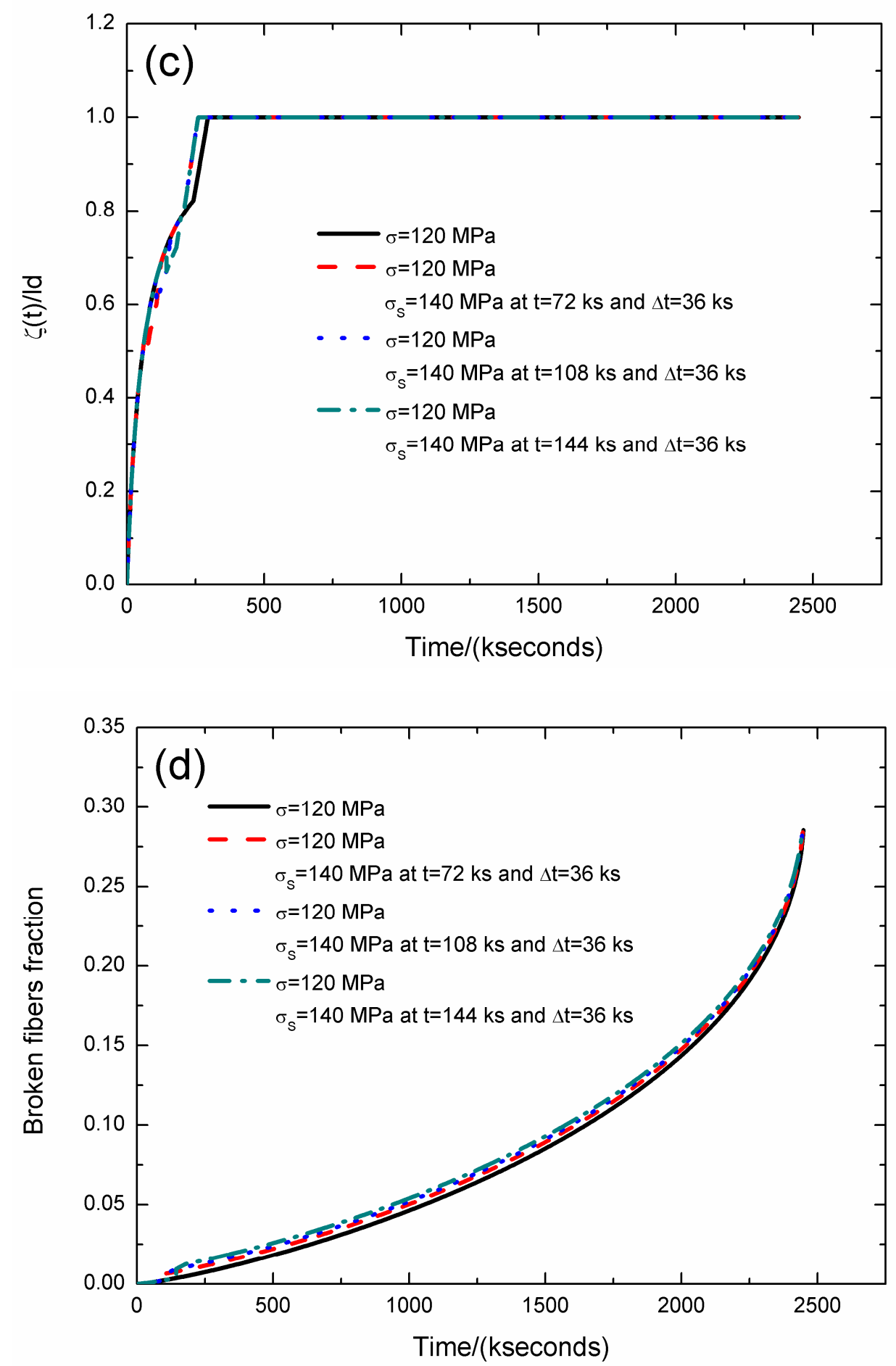

Figure 4. (a) The strain versus the time curves; (b) the fiber/matrix interface debonding length versus the time curves; (c) the fiber/matrix interface oxidation length versus the time curves; and (d) the broken fibers fraction versus the time curves of $\mathrm{SiC} / \mathrm{SiC}$ composite under stress-rupture loading of constant stress of $\sigma=120 \mathrm{MPa}, \sigma_{\mathrm{S}}=140 \mathrm{MPa}$ at $t=72,108,144$ kseconds and $\Delta \mathrm{t}=26 \mathrm{kseconds}$ at $800{ }^{\circ} \mathrm{C}$ in air atmosphere. 
Table 2. The strain, fiber/matrix interface debonding and oxidation length, and broken fibers fraction of $\mathrm{SiC} / \mathrm{SiC}$ composite under stress-rupture loading of constant stress of $\sigma=120 \mathrm{MPa}, \sigma_{\mathrm{S}}=140 \mathrm{MPa}$ at $t=72,108,144$ kseconds and $\Delta t=36$ kseconds at $800^{\circ} \mathrm{C}$ in air atmosphere.

\begin{tabular}{|c|c|c|c|c|c|c|c|c|}
\hline$\sigma / \mathrm{MPa}$ & 120 & 120 & 120 & 120 & 120 & & & \\
\hline$t /$ kseconds & 0 & 36 & 242.7 & 295.3 & 2447.9 & & & \\
\hline$\varepsilon_{\mathrm{c}} / \%$ & 0.053 & 0.07 & 0.163 & 0.17 & 0.201 & & & \\
\hline $2 l_{\mathrm{d}} / l_{\mathrm{c}}$ & 0.203 & 0.322 & 1.0 & 1.0 & 1.0 & & & \\
\hline$\zeta / l_{\mathrm{d}}$ & 0 & 0.380 & 0.822 & 1.0 & 1.0 & & & \\
\hline$P$ & $1 \times 10^{-6}$ & $6.5 \times 10^{-4}$ & 0.007 & 0.009 & 0.285 & & & \\
\hline$\sigma / \mathrm{MPa}$ & 120 & 120 & 140 & 140 & 120 & 120 & 120 & 120 \\
\hline$t /$ kseconds & 0 & 72 & 72 & 108 & 108 & 205.7 & 259.4 & 2446.2 \\
\hline$\varepsilon_{\mathrm{c}} / \%$ & 0.053 & 0.087 & 0.115 & 0.138 & 0.115 & 0.162 & 0.171 & 0.201 \\
\hline $2 l_{\mathrm{d}} / l_{\mathrm{c}}$ & 0.203 & 0.44 & 0.558 & 0.694 & 0.694 & 1.0 & 1.0 & 1.0 \\
\hline$\zeta / l_{\mathrm{d}}$ & 0 & 0.555 & 0.498 & 0.601 & 0.601 & 0.794 & 1.0 & 1.0 \\
\hline P & $1 \times 10^{-6}$ & 0.0015 & 0.0039 & 0.0065 & 0.0065 & 0.0097 & 0.011 & 0.285 \\
\hline$\sigma / \mathrm{MPa}$ & 120 & 120 & 140 & 140 & 120 & 120 & 200 & 200 \\
\hline$t /$ kseconds & 0 & 108 & 108 & 144 & 144 & 205.7 & 259.4 & 2445.2 \\
\hline$\varepsilon_{\mathrm{c}} / \%$ & 0.053 & 0.103 & 0.138 & 0.16 & 0.133 & 0.162 & 0.171 & 0.201 \\
\hline $2 l_{\mathrm{d}} / l_{\mathrm{c}}$ & 0.203 & 0.558 & 0.694 & 0.829 & 0.829 & 1.0 & 1.0 & 1.0 \\
\hline$\zeta / l_{\mathrm{d}}$ & 0 & 0.656 & 0.601 & 0.671 & 0.671 & 0.793 & 1.0 & 1.0 \\
\hline P & $1 \times 10^{-6}$ & 0.002 & 0.006 & 0.009 & 0.009 & 0.011 & 0.013 & 0.285 \\
\hline$\sigma / \mathrm{MPa}$ & 120 & 120 & 140 & 140 & 120 & 120 & 120 & 120 \\
\hline$t /$ kseconds & 0 & 144 & 144 & 180 & 180 & 205.7 & 259.4 & 2444.1 \\
\hline$\varepsilon_{\mathrm{c}} / \%$ & 0.053 & 0.12 & 0.16 & 0.182 & 0.152 & 0.162 & 0.171 & 0.201 \\
\hline $2 l_{\mathrm{d}} / l_{\mathrm{c}}$ & 0.203 & 0.677 & 0.829 & 0.964 & 0.964 & 1.0 & 1.0 & 1.0 \\
\hline$\zeta / l_{\mathrm{d}}$ & 0 & 0.722 & 0.671 & 0.72 & 0.72 & 0.793 & 1.0 & 1.0 \\
\hline$P$ & $1 \times 10^{-6}$ & 0.003 & 0.009 & 0.012 & 0.012 & 0.013 & 0.015 & 0.285 \\
\hline
\end{tabular}

When the stochastic loading time is $t=72 \mathrm{kseconds}$, the stress-rupture lifetime is $t=2446.2$ kseconds; the time for the interface complete debonding is $t=205.7$ kseconds; the time for the interface complete oxidation is $t=259.4$ kseconds; the failure strain is $\varepsilon_{\mathrm{C}}=0.201 \%$; and the broken fibers fraction is $P=0.285$. When the stochastic loading time increases from $t=72$ to $144 \mathrm{kseconds}$, the stress-rupture lifetime decreases, and the time for the interface complete debonding and oxidation remains the same.

The strain, fiber/matrix interface debonding and oxidation length, and the broken fibers fraction of $\mathrm{SiC} / \mathrm{SiC}$ composite under stress-rupture loading of constant stress of $\sigma=120 \mathrm{MPa}, \sigma_{\mathrm{S}}=140 \mathrm{MPa}$ at $t=36$ kseconds and $\Delta t=72,108,144$ kseconds at $800{ }^{\circ} \mathrm{C}$ in air atmosphere are shown in Figure 5 and Table 3.

When the stochastic loading time spacing is $\Delta t=72 \mathrm{kseconds}$, the stress-rupture lifetime is $t=$ 2446.2 kseconds; the time for the interface complete debonding is $t=205.7 \mathrm{kseconds}$; the time for the interface complete oxidation is $t=259.4$ kseconds; the failure strain is $\varepsilon_{\mathrm{c}}=0.201 \%$; and the broken fibers fraction is $P=0.285$. When the stochastic loading time spacing increases from $\Delta t=72$ to 144 kseconds, the stress-rupture lifetime decreases, and the time for the interface complete debonding and oxidation remains the same. 

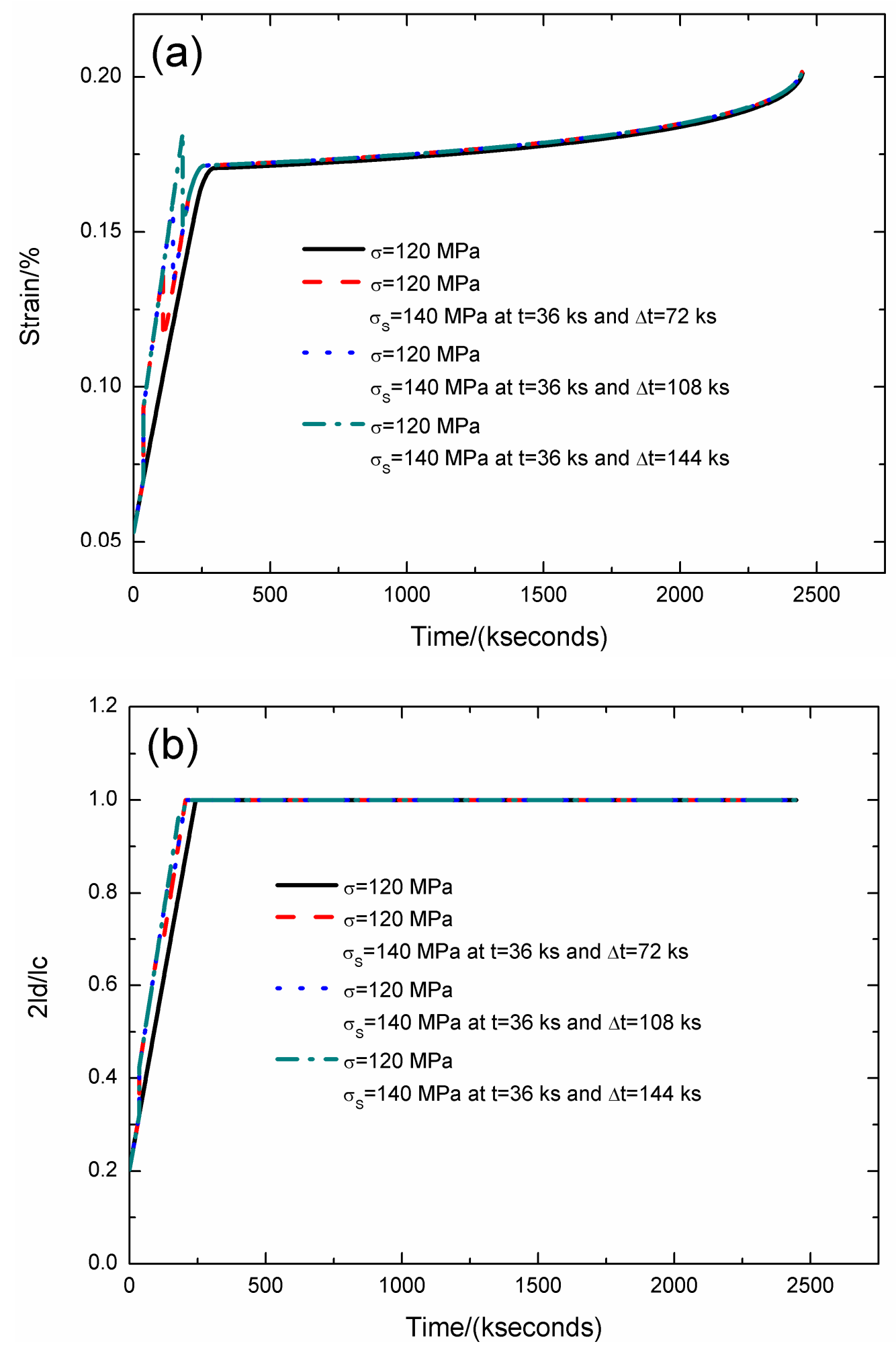

Figure 5. Cont. 

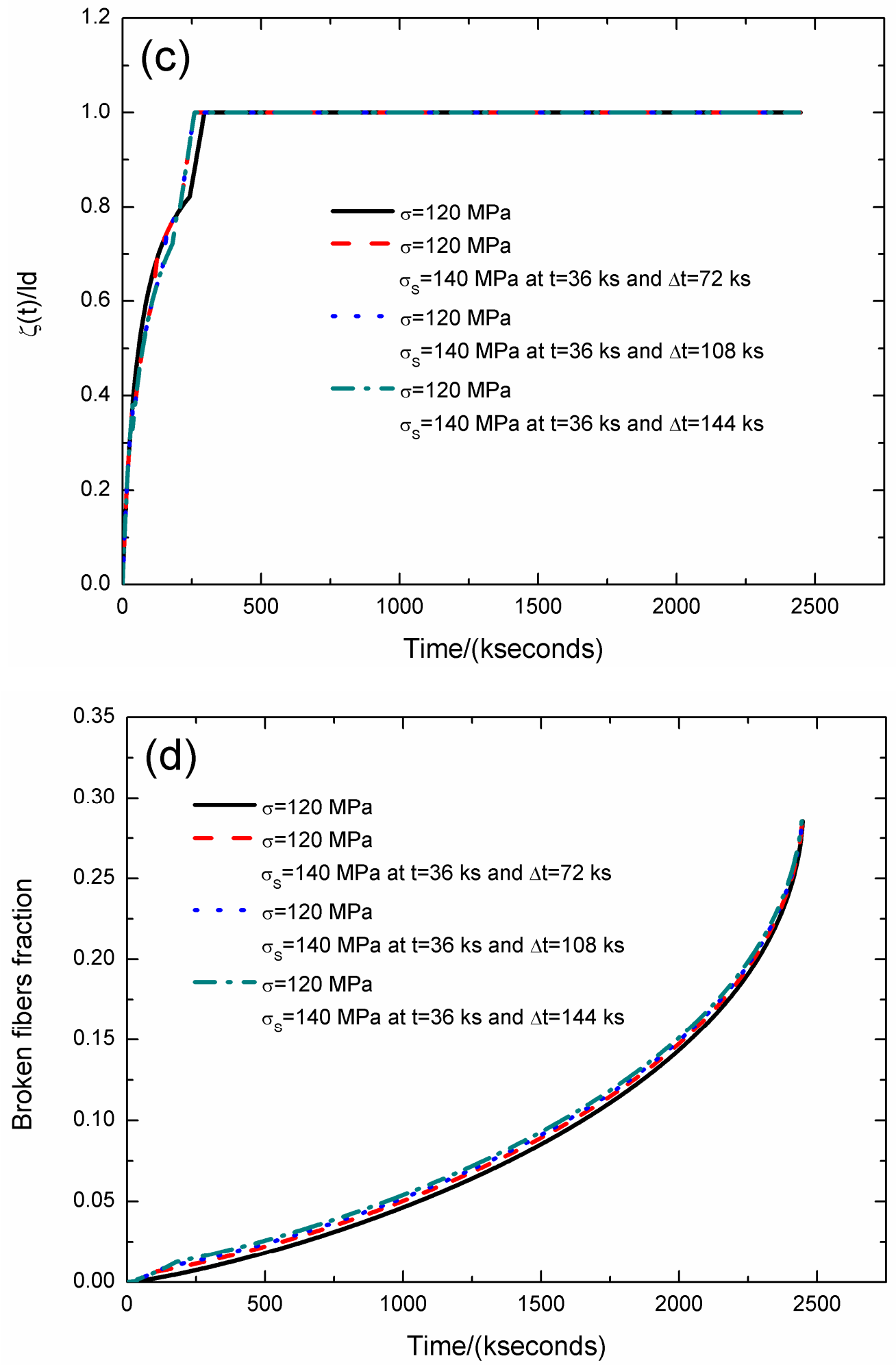

Figure 5. (a) The strain versus the time curves; (b) the fiber/matrix interface debonding length versus the time curves; (c) the fiber/matrix interface oxidation length versus the time curves; and (d) the broken fibers fraction versus the time curves of $\mathrm{SiC} / \mathrm{SiC}$ composite under stress-rupture loading of constant stress of $\sigma=120 \mathrm{MPa}, \sigma_{\mathrm{S}}=140 \mathrm{MPa}$ at $t=36 \mathrm{kseconds}$ and $\Delta \mathrm{t}=72,108,144 \mathrm{kseconds}$ at $800{ }^{\circ} \mathrm{C}$ in air atmosphere. 
Table 3. The strain, fiber/matrix interface debonding and oxidation length, and broken fibers fraction of $\mathrm{SiC} / \mathrm{SiC}$ composite under stress-rupture loading of constant stress of $\sigma=120 \mathrm{MPa}, \sigma_{\mathrm{S}}=140 \mathrm{MPa}$ at $t=36$ kseconds and $\Delta t=72,108,144 \mathrm{kseconds}$ at $800^{\circ} \mathrm{C}$ in air atmosphere.

\begin{tabular}{ccccccccc}
\hline$\sigma / \mathrm{MPa}$ & $\mathbf{1 2 0}$ & $\mathbf{1 2 0}$ & $\mathbf{1 2 0}$ & $\mathbf{1 2 0}$ & $\mathbf{1 2 0}$ & & & \\
\hline$t / \mathrm{kseconds}$ & 0 & 36 & 242.7 & 295.3 & 2447.9 & & & \\
\hline$\varepsilon_{\mathrm{c}} / \%$ & 0.053 & 0.07 & 0.163 & 0.17 & 0.201 & & & \\
$2 l_{\mathrm{d}} / l_{\mathrm{c}}$ & 0.203 & 0.322 & 1.0 & 1.0 & 1.0 & & & \\
$\zeta / l_{\mathrm{d}}$ & 0 & 0.380 & 0.822 & 1.0 & 1.0 & & & \\
$P$ & $1 \times 10^{-6}$ & $6.5 \times 10^{-4}$ & 0.007 & 0.009 & 0.285 & & & 120 \\
\hline$\sigma / \mathrm{MPa}$ & 120 & 120 & 140 & 140 & 120 & 120 & 120 \\
$t / \mathrm{kseconds}$ & 0 & 36 & 36 & 108 & 108 & 205.7 & 259.4 & 2446.2 \\
\hline$\varepsilon_{\mathrm{c}} / \%$ & 0.053 & 0.07 & 0.093 & 0.138 & 0.115 & 0.162 & 0.171 & 0.201 \\
$2 l_{\mathrm{d}} / l_{\mathrm{c}}$ & 0.203 & 0.322 & 0.423 & 0.694 & 0.694 & 1.0 & 1.0 & 1.0 \\
$\zeta / l_{\mathrm{d}}$ & 0 & 0.380 & 0.328 & 0.601 & 0.601 & 0.794 & 1.0 & 1.0 \\
$P$ & $1 \times 10^{-6}$ & $6.5 \times 10^{-4}$ & 0.001 & 0.006 & 0.006 & 0.009 & 0.012 & 0.285 \\
\hline$\sigma / \mathrm{MPa}$ & 120 & 120 & 140 & 140 & 120 & 120 & 200 & 200 \\
$t / \mathrm{kseconds}$ & 0 & 36 & 36 & 144 & 144 & 205.7 & 259.4 & 2445.2 \\
\hline$\varepsilon_{\mathrm{c}} / \%$ & 0.053 & 0.07 & 0.093 & 0.160 & 0.133 & 0.162 & 0.171 & 0.201 \\
$2 l_{\mathrm{d}} / l_{\mathrm{c}}$ & 0.203 & 0.322 & 0.423 & 0.829 & 0.829 & 1.0 & 1.0 & 1.0 \\
$\zeta / l_{\mathrm{d}}$ & 0 & 0.380 & 0.328 & 0.671 & 0.671 & 0.793 & 1.0 & 1.0 \\
$P$ & $1 \times 10^{-6}$ & $6.5 \times 10^{-4}$ & 0.001 & 0.009 & 0.009 & 0.011 & 0.013 & 0.285 \\
\hline$\sigma / \mathrm{MPa}$ & 120 & 120 & 140 & 140 & 120 & 120 & 120 & 120 \\
$t / \mathrm{kseconds}$ & 0 & 36 & 36 & 180 & 180 & 205.7 & 259.4 & 2444.1 \\
\hline$\varepsilon_{\mathrm{c}} / \%$ & 0.053 & 0.07 & 0.093 & 0.182 & 0.152 & 0.162 & 0.171 & 0.201 \\
$2 l_{\mathrm{d}} / l_{\mathrm{c}}$ & 0.203 & 0.322 & 0.423 & 0.964 & 0.964 & 1.0 & 1.0 & 1.0 \\
$\zeta / l_{\mathrm{d}}$ & 0 & 0.380 & 0.328 & 0.72 & 0.72 & 0.794 & 1.0 & 1.0 \\
$P$ & $1 \times 10^{-6}$ & $6.5 \times 10^{-4}$ & 0.001 & 0.012 & 0.012 & 0.013 & 0.015 & 0.285 \\
\hline
\end{tabular}

\subsection{Case III}

For the stochastic loading of Case III, the strain, fiber/matrix interface debonding and oxidation length, and the broken fibers fraction of $\mathrm{SiC} / \mathrm{SiC}$ composite under stress-rupture loading of constant stress of $\sigma=120 \mathrm{MPa}, \sigma_{\mathrm{S}}=130 / 140,140 / 150,150 / 160 \mathrm{MPa}$ at $t=36 / 108 \mathrm{kseconds}$ and $\Delta t=36 \mathrm{kseconds}$ at $800{ }^{\circ} \mathrm{C}$ in air atmosphere are shown in Figure 6 and Table 4 . When the stochastic loading stress increases, the stress-rupture lifetime decreases, and the time for the interface complete debonding and oxidation decreases.

When the stochastic loading stress is $\sigma_{\mathrm{S}}=130,140 \mathrm{MPa}$, the stress-rupture lifetime is $t=2444.1$ kseconds; the time for the interface complete debonding is $t=205.7 \mathrm{kseconds}$; the time for the interface complete oxidation is $t=259.4$ kseconds; the failure strain is $\varepsilon_{\mathrm{c}}=0.2 \%$; and the broken fibers fraction is $P=0.285$. When the stochastic loading stress is $\sigma_{\mathrm{S}}=140,150 \mathrm{MPa}$, the stress-rupture lifetime is $t=2438.1$ kseconds; the time for the interface complete debonding is $t=197.3 \mathrm{kseconds}$; the time for the interface complete oxidation is $t=251.3$ kseconds; the failure strain is $\varepsilon_{\mathrm{c}}=0.2 \%$; and the broken fibers fraction is $P=0.285$. When the stochastic loading stress is $\sigma_{\mathrm{S}}=150,160 \mathrm{MPa}$, the stress-rupture lifetime is $t=2425.9$ kseconds; the time for the interface complete debonding is $t=192.6 \mathrm{kseconds}$; the time for the interface complete oxidation is $t=246.8 \mathrm{kseconds}$; the failure strain is $\varepsilon_{\mathrm{c}}=0.199 \%$; and the broken fibers fraction is $P=0.285$. 

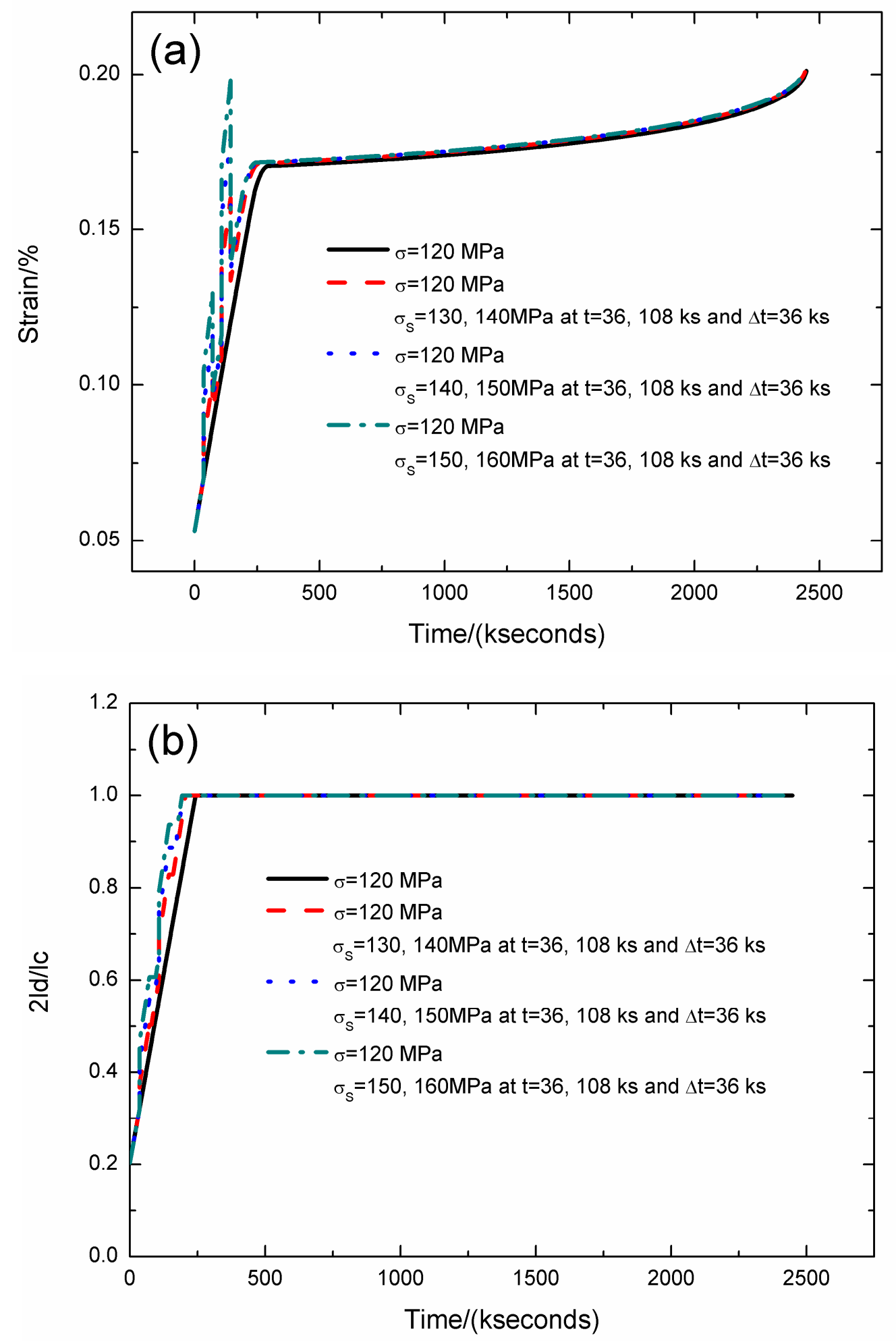

Figure 6. Cont. 

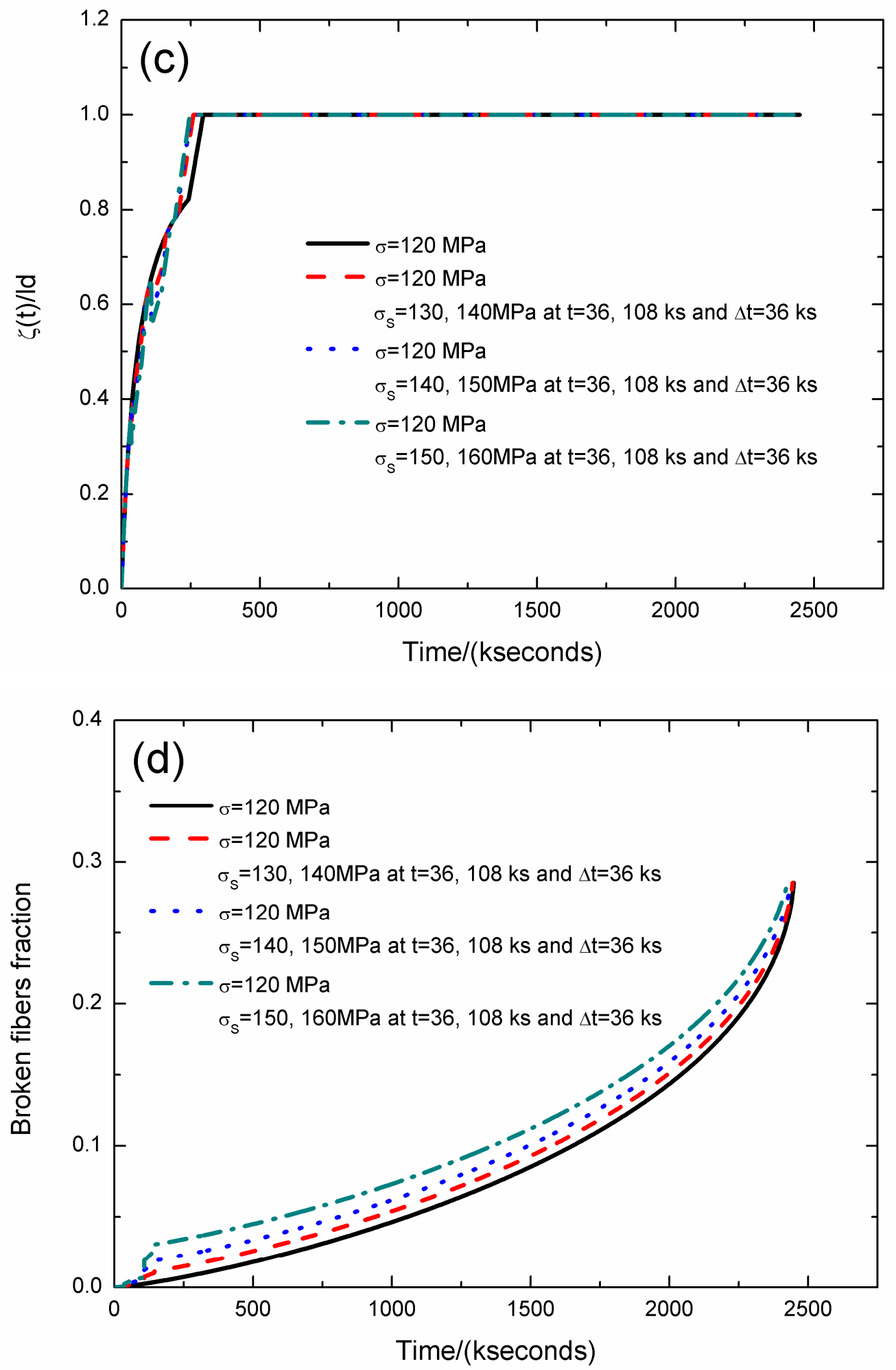

Figure 6. (a) The strain versus the time curves; (b) the fiber/matrix interface debonding length versus the time curves; (c) the fiber/matrix interface oxidation length versus the time curves; and (d) the broken fibers fraction versus the time curves of $\mathrm{SiC} / \mathrm{SiC}$ composite under stress-rupture loading of constant stress of $\sigma=120 \mathrm{MPa}, \sigma_{\mathrm{S}}=130 / 140,140 / 150,150 / 160 \mathrm{MPa}$ at $t=36 / 108 \mathrm{kseconds}$ and $\Delta \mathrm{t}=36 \mathrm{kseconds}$ at $800{ }^{\circ} \mathrm{C}$ in air atmosphere. 
Table 4. The strain, fiber/matrix interface debonding and oxidation length, and broken fibers fraction of $\mathrm{SiC} / \mathrm{SiC}$ composite under stress-rupture loading of constant stress of $\sigma=120 \mathrm{MPa}, \sigma_{\mathrm{S}}=130 / 140$, $140 / 150,150 / 160 \mathrm{MPa}$ at $t=36 / 108 \mathrm{kseconds}$ and $\Delta \mathrm{t}=36 \mathrm{kseconds}$ at $800{ }^{\circ} \mathrm{C}$ in air atmosphere.

\begin{tabular}{|c|c|c|c|c|c|c|c|c|c|c|c|c|}
\hline$\sigma / \mathbf{M P a}$ & 120 & 120 & 120 & 120 & 120 & & & & & & & \\
\hline$t /$ kseconds & 0 & 36 & 242.7 & 295.3 & 2447.9 & & & & & & & \\
\hline$\varepsilon_{\mathrm{c}} / \%$ & 0.053 & 0.07 & 0.163 & 0.17 & 0.201 & & & & & & & \\
\hline $2 l_{\mathrm{d}} / l_{\mathrm{c}}$ & 0.203 & 0.322 & 1.0 & 1.0 & 1.0 & & & & & & & \\
\hline$\zeta / l_{\mathrm{d}}$ & 0 & 0.380 & 0.822 & 1.0 & 1.0 & & & & & & & \\
\hline$P$ & $1 \times 10^{-6}$ & $6.5 \times 10^{-4}$ & 0.007 & 0.009 & 0.285 & & & & & & & \\
\hline$\sigma / \mathrm{MPa}$ & 120 & 120 & 130 & 130 & 120 & 120 & 140 & 140 & 120 & 120 & 120 & 120 \\
\hline$t /$ kseconds & 0 & 36 & 36 & 72 & 72 & 108 & 108 & 144 & 144 & 205.7 & 259.4 & 2444.1 \\
\hline$\varepsilon_{\mathrm{c}} / \%$ & 0.053 & 0.07 & 0.082 & 0.101 & 0.092 & 0.109 & 0.138 & 0.16 & 0.133 & 0.162 & 0.171 & 0.2 \\
\hline $2 l_{\mathrm{d}} / l_{\mathrm{c}}$ & 0.203 & 0.322 & 0.375 & 0.503 & 0.503 & 0.603 & 0.694 & 0.829 & 0.829 & 1.0 & 1.0 & 1.0 \\
\hline$\zeta / l_{\mathrm{d}}$ & 0 & 0.380 & 0.352 & 0.525 & 0.525 & 0.656 & 0.602 & 0.671 & 0.671 & 0.794 & 1.0 & 1.0 \\
\hline$P$ & $1 \times 10^{-6}$ & $6.5 \times 10^{-4}$ & 0.001 & 0.0025 & 0.0025 & 0.0035 & 0.0074 & 0.0103 & 0.0113 & 0.013 & 0.015 & 0.285 \\
\hline$\sigma / \mathrm{MPa}$ & 120 & 120 & 140 & 140 & 120 & 120 & 150 & 150 & 120 & 120 & 120 & 120 \\
\hline$t /$ kseconds & 0 & 36 & 36 & 72 & 72 & 108 & 108 & 144 & 144 & 197.3 & 251.3 & 2438.1 \\
\hline$\varepsilon_{\mathrm{c}} / \%$ & 0.053 & 0.07 & 0.093 & 0.115 & 0.096 & 0.113 & 0.154 & 0.179 & 0.137 & 0.162 & 0.171 & 0.2 \\
\hline $2 l_{\mathrm{d}} / l_{\mathrm{c}}$ & 0.203 & 0.322 & 0.423 & 0.558 & 0.558 & 0.635 & 0.747 & 0.887 & 0.887 & 1.0 & 1.0 & 1.0 \\
\hline$\zeta / l_{\mathrm{d}}$ & 0 & 0.380 & 0.328 & 0.498 & 0.498 & 0.656 & 0.576 & 0.647 & 0.647 & 0.786 & 1.0 & 1.0 \\
\hline$P$ & $1 \times 10^{-6}$ & $6.5 \times 10^{-4}$ & 0.0016 & 0.0039 & 0.0039 & 0.0049 & 0.0123 & 0.0168 & 0.0192 & 0.021 & 0.023 & 0.285 \\
\hline$\sigma / \mathrm{MPa}$ & 120 & 120 & 150 & 150 & 120 & 120 & 160 & 160 & 120 & 120 & 120 & 120 \\
\hline$t /$ kseconds & 0 & 36 & 36 & 72 & 72 & 108 & 108 & 144 & 144 & 192.6 & 246.8 & 2425.9 \\
\hline$\varepsilon_{\mathrm{c}} / \%$ & 0.053 & 0.07 & 0.104 & 0.129 & 0.098 & 0.116 & 0.170 & 0.198 & 0.138 & 0.162 & 0.171 & 0.199 \\
\hline $2 l_{\mathrm{d}} / l_{\mathrm{c}}$ & 0.203 & 0.322 & 0.467 & 0.607 & 0.607 & 0.656 & 0.792 & 0.936 & 0.936 & 1.0 & 1.0 & 1.0 \\
\hline$\zeta / l_{\mathrm{d}}$ & 0 & 0.380 & 0.307 & 0.473 & 0.473 & 0.656 & 0.553 & 0.624 & 0.624 & 0.781 & 1.0 & 1.0 \\
\hline$P$ & $1 \times 10^{-6}$ & $6.5 \times 10^{-4}$ & 0.002 & 0.0059 & 0.0059 & 0.0069 & 0.019 & 0.0269 & 0.0305 & 0.0324 & 0.034 & 0.285 \\
\hline
\end{tabular}

The strain, fiber/matrix interface debonding and oxidation length, and the broken fibers fraction of $\mathrm{SiC} / \mathrm{SiC}$ composite under stress-rupture loading of constant stress of $\sigma=120 \mathrm{MPa}, \sigma_{\mathrm{S}}=140 / 160 \mathrm{MPa}$ at $t=72 / 144,108 / 180,144 / 216 \mathrm{kseconds}$ and $\Delta t=36 \mathrm{kseconds}$ at $800{ }^{\circ} \mathrm{C}$ in air atmosphere are shown in Figure 7 and Table 5 . When the stochastic loading time increases, the stress-rupture lifetime decreases, and the time for the interface complete debonding increases.

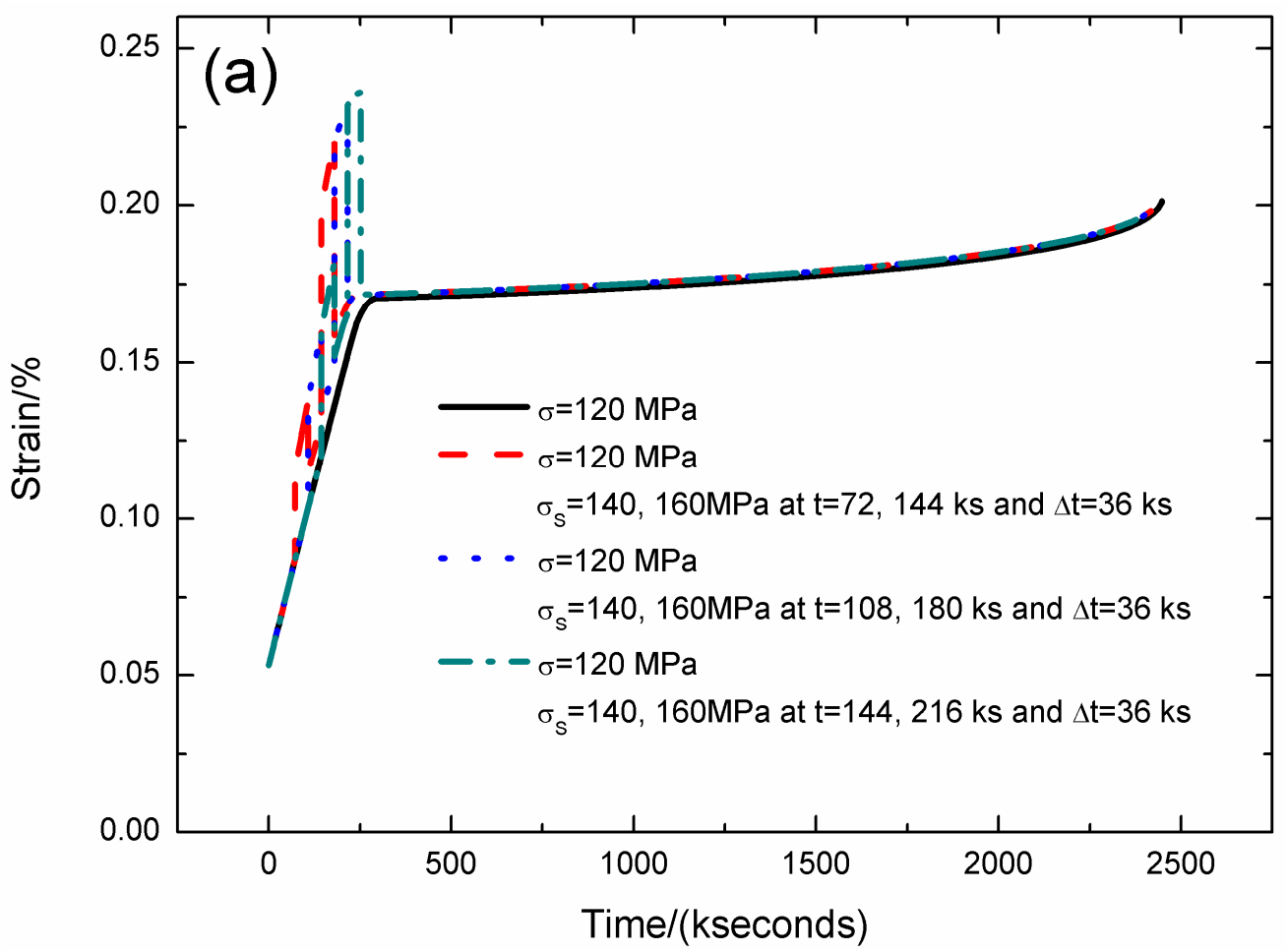

Figure 7. Cont. 

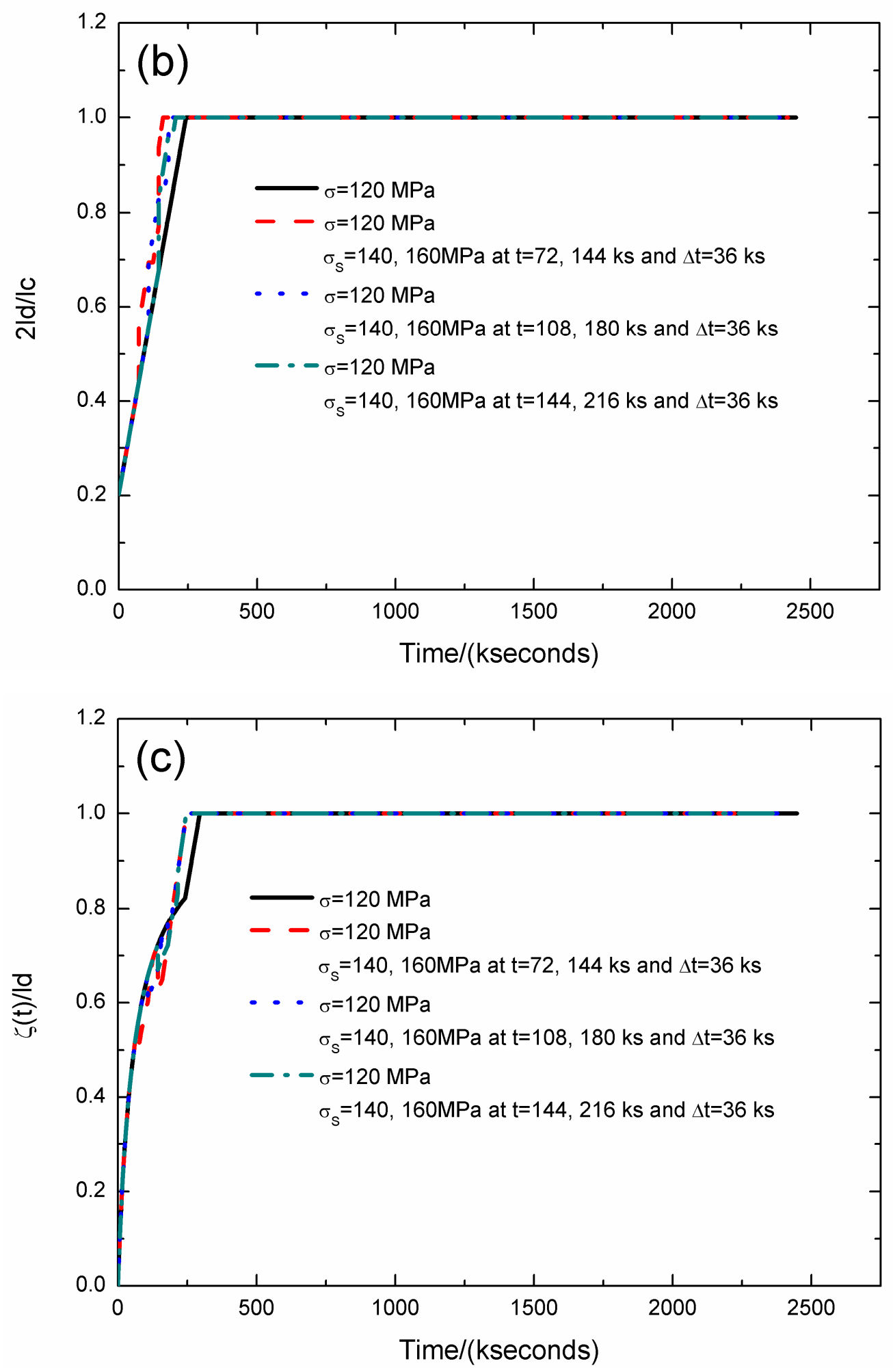

Figure 7. Cont. 


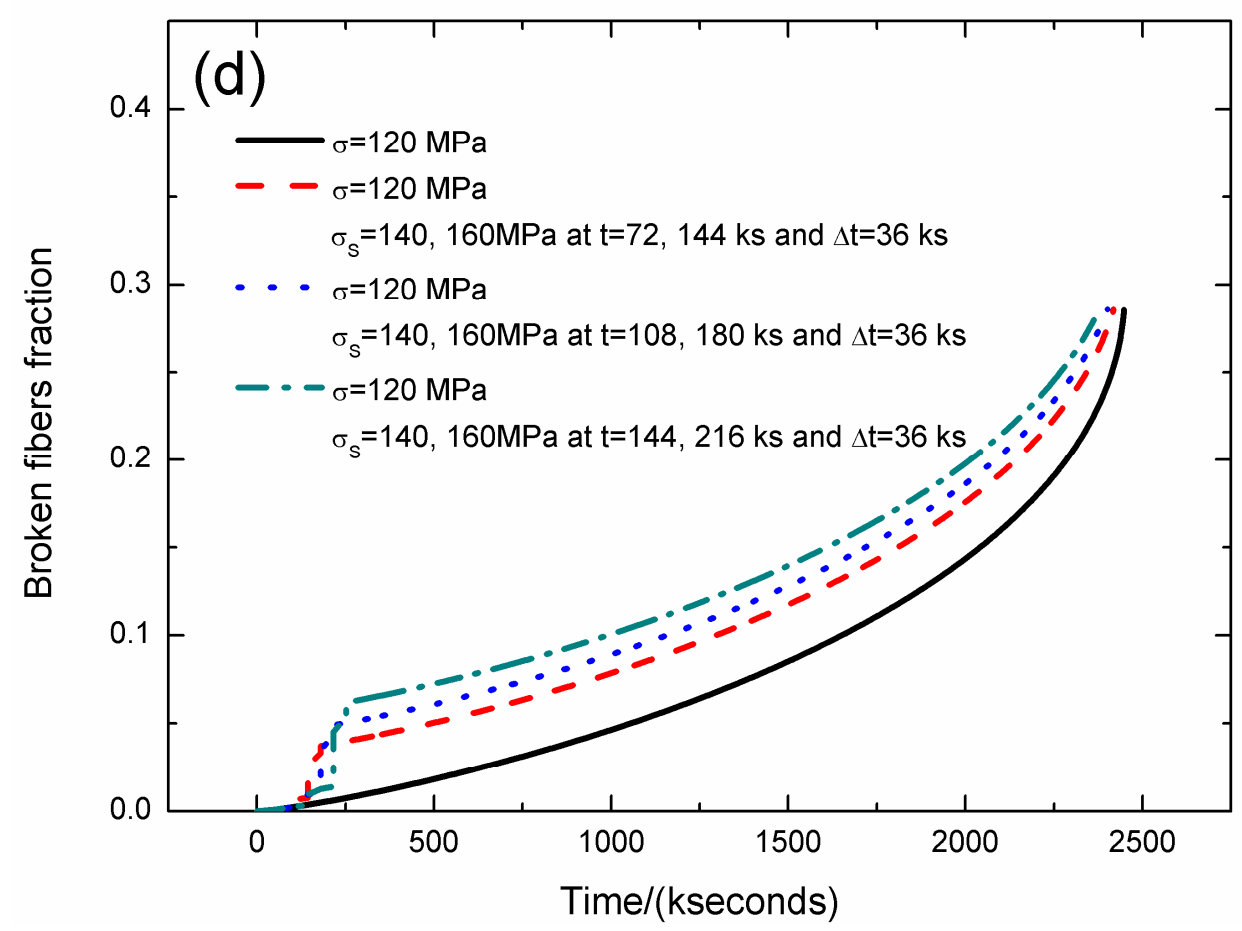

Figure 7. (a) The strain versus the time curves; (b) the fiber/matrix interface debonding length versus the time curves; (c) the fiber/matrix interface oxidation length versus the time curves; and (d) the broken fibers fraction versus the time curves of $\mathrm{SiC} / \mathrm{SiC}$ composite under stress-rupture loading of constant stress of $\sigma=120 \mathrm{MPa}, \sigma_{\mathrm{S}}=140 / 160 \mathrm{MPa}$ at $t=72 / 144,108 / 180,144 / 216 \mathrm{kseconds}$ and $\Delta \mathrm{t}=36 \mathrm{kseconds}$ at $800{ }^{\circ} \mathrm{C}$ in air atmosphere.

Table 5. The strain, fiber/matrix interface debonding and oxidation length, and broken fibers fraction of $\mathrm{SiC} / \mathrm{SiC}$ composite under stress-rupture loading of constant stress of $\sigma=120 \mathrm{MPa}, \sigma_{\mathrm{S}}=140 / 160 \mathrm{MPa}$ at $t=72 / 144,108 / 180,144 / 216 \mathrm{kseconds}$ and $\Delta \mathrm{t}=36 \mathrm{kseconds}$ at $800^{\circ} \mathrm{C}$ in air atmosphere.

\begin{tabular}{|c|c|c|c|c|c|c|c|c|c|c|c|c|}
\hline$\sigma / \mathrm{MPa}$ & 120 & 120 & 120 & 120 & 120 & & & & & & & \\
\hline$t / \mathrm{kseconds}$ & 0 & 36 & 242.7 & 295.3 & 2447.9 & & & & & & & \\
\hline$\varepsilon_{\mathrm{c}} / \%$ & 0.053 & 0.07 & 0.163 & 0.17 & 0.201 & & & & & & & \\
\hline $2 l_{\mathrm{d}} / l_{\mathrm{c}}$ & 0.203 & 0.322 & 1.0 & 1.0 & 1.0 & & & & & & & \\
\hline$\zeta / l_{\mathrm{d}}$ & 0 & 0.380 & 0.822 & 1.0 & 1.0 & & & & & & & \\
\hline$P$ & $1 \times 10^{-6}$ & $6.5 \times 10^{-4}$ & 0.007 & 0.009 & 0.285 & & & & & & & \\
\hline$\sigma / \mathrm{MPa}$ & 120 & 120 & 140 & 140 & 120 & 120 & 160 & 160 & 160 & 120 & 120 & 120 \\
\hline$t /$ kseconds & 0 & 72 & 72 & 108 & 108 & 144 & 144 & 160 & 180 & 180 & 246.8 & 2418.4 \\
\hline$\varepsilon_{\mathrm{c}} / \%$ & 0.053 & 0.087 & 0.115 & 0.138 & 0.114 & 0.132 & 0.198 & 0.209 & 0.219 & 0.157 & 0.171 & 0.198 \\
\hline $2 l_{\mathrm{d}} / l_{\mathrm{c}}$ & 0.203 & 0.44 & 0.558 & 0.694 & 0.694 & 0.77 & 0.936 & 1.0 & 1.0 & 1.0 & 1.0 & 1.0 \\
\hline$\zeta / l_{\mathrm{d}}$ & 0 & 0.556 & 0.498 & 0.601 & 0.601 & 0.722 & 0.624 & 0.649 & 0.73 & 0.73 & 1.0 & 1.0 \\
\hline$P$ & $1 \times 10^{-6}$ & 0.0015 & 0.0039 & 0.00654 & 0.00654 & 0.00766 & 0.025 & 0.029 & 0.033 & 0.037 & 0.039 & 0.285 \\
\hline$\sigma / \mathrm{MPa}$ & 120 & 120 & 140 & 140 & 120 & 120 & 160 & 160 & 120 & 120 & 120 & \\
\hline$t /$ kseconds & 0 & 108 & 108 & 144 & 144 & 180 & 180 & 216 & 216 & 246.8 & 2400.9 & \\
\hline$\varepsilon_{\mathrm{c}} / \%$ & 0.053 & 0.103 & 0.138 & 0.16 & 0.133 & 0.15 & 0.219 & 0.231 & 0.168 & 0.171 & 0.197 & \\
\hline $2 l_{\mathrm{d}} / l_{\mathrm{c}}$ & 0.203 & 0.558 & 0.694 & 0.829 & 0.829 & 0.904 & 1.0 & 1.0 & 1.0 & 1.0 & 1.0 & \\
\hline$\zeta / l_{\mathrm{d}}$ & 0 & 0.656 & 0.601 & 0.671 & 0.671 & 0.768 & 0.73 & 0.876 & 0.876 & 1.0 & 1.0 & \\
\hline$P$ & $1 \times 10^{-6}$ & 0.0025 & 0.0065 & 0.009 & 0.009 & 0.01 & 0.035 & 0.043 & 0.048 & 0.05 & 0.285 & \\
\hline$\sigma / \mathrm{MPa}$ & 120 & 120 & 140 & 140 & 120 & 120 & 160 & 160 & 120 & 120 & & \\
\hline$t /$ kseconds & 0 & 144 & 144 & 180 & 180 & 216 & 216 & 252 & 252 & 2376.8 & & \\
\hline$\varepsilon_{\mathrm{c}} / \%$ & 0.053 & 0.16 & 0.16 & 0.182 & 0.152 & 0.165 & 0.231 & 0.236 & 0.171 & 0.195 & & \\
\hline $2 l_{\mathrm{d}} / l_{\mathrm{c}}$ & 0.203 & 0.676 & 0.829 & 0.964 & 0.964 & 1.0 & 1.0 & 1.0 & 1.0 & 1.0 & & \\
\hline$\zeta / l_{\mathrm{d}}$ & 0 & 0.722 & 0.671 & 0.72 & 0.72 & 0.833 & 0.876 & 1.0 & 1.0 & 1.0 & & \\
\hline$P$ & $1 \times 10^{-6}$ & 0.0036 & 0.0094 & 0.012 & 0.012 & 0.013 & 0.045 & 0.054 & 0.061 & 0.285 & & \\
\hline
\end{tabular}

When the stochastic loading time is $t=72$ and 144 kseconds, the stress-rupture lifetime is $t=2418.4$ kseconds; the time for the interface complete debonding is $t=160 \mathrm{kseconds}$ at stochastic loading stress of $\sigma_{\mathrm{S}}=160 \mathrm{MPa}$; the time for the interface complete oxidation is $t=246.8 \mathrm{kseconds}$ at constant loading stress of $\sigma=120 \mathrm{MPa}$; the failure strain is $\varepsilon_{\mathrm{c}}=0.198 \%$; and the broken fibers fraction 
is $P=0.285$. When the stochastic loading time is $t=144$ and $216 \mathrm{kseconds}$, the stress-rupture lifetime is $t=2376.8$ kseconds; the time for the interface complete debonding is $t=205.7 \mathrm{kseconds}$ at constant stress of $\sigma=120 \mathrm{MPa}$; the time for the interface complete oxidation is $t=246.8 \mathrm{kseconds}$; the failure strain is $\varepsilon_{\mathrm{c}}=0.195 \%$; and the broken fibers fraction is $P=0.285$.

The strain, fiber/matrix interface debonding and oxidation length, and the broken fibers fraction of $\mathrm{SiC} / \mathrm{SiC}$ composite under stress-rupture loading of constant stress of $\sigma=120 \mathrm{MPa}, \sigma_{\mathrm{S}}=140 / 160 \mathrm{MPa}$ at $t=36 / 144,36 / 180,36 / 216 \mathrm{kseconds}$ and $\Delta t=72,108,144 \mathrm{kseconds}$ at $800^{\circ} \mathrm{C}$ in air atmosphere are shown in Figure 8 and Table 6 . When the stochastic loading time spacing increases, the stress-rupture lifetime decreases, and the time for the interface complete debonding increases.
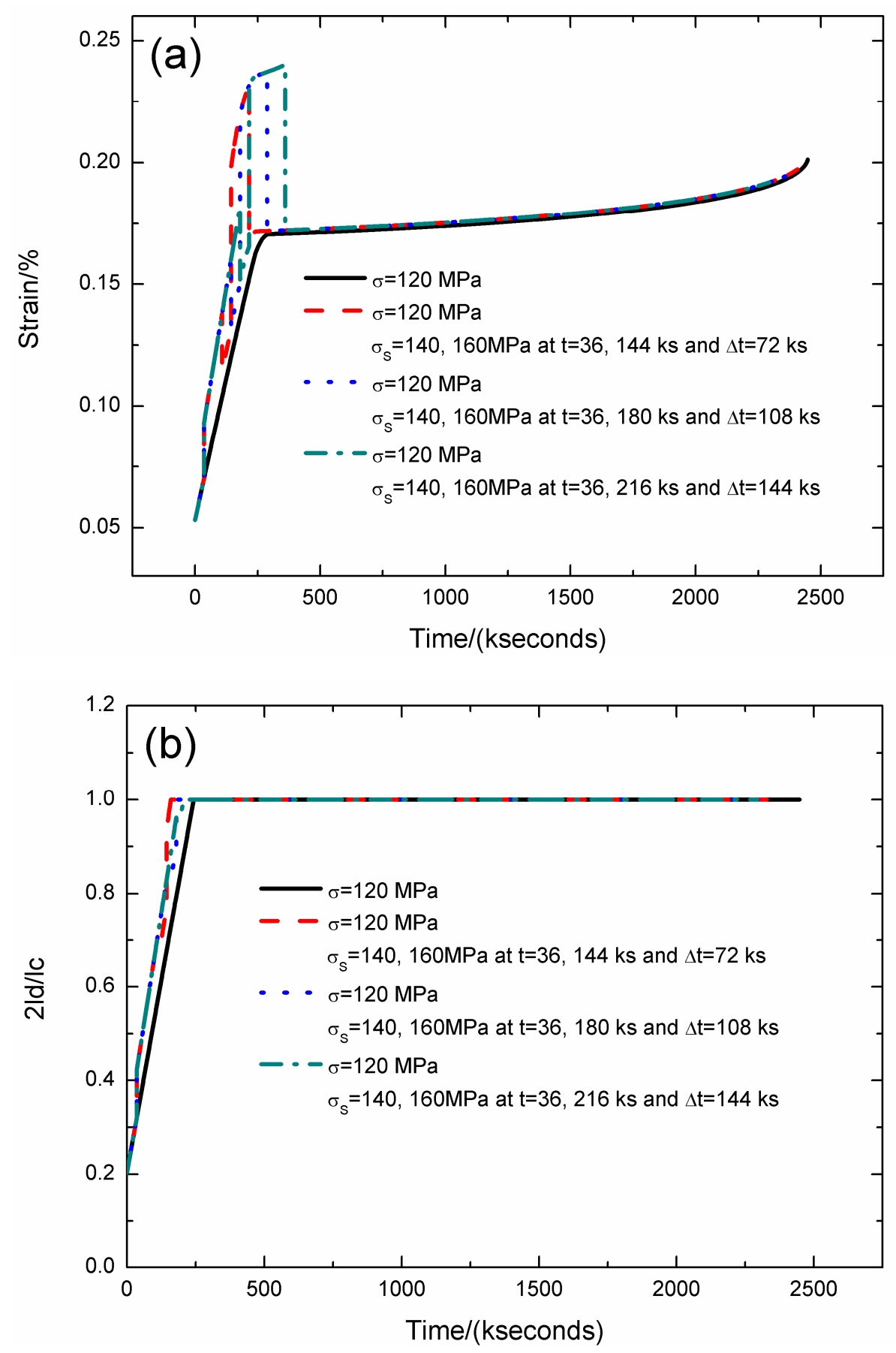

Figure 8. Cont. 

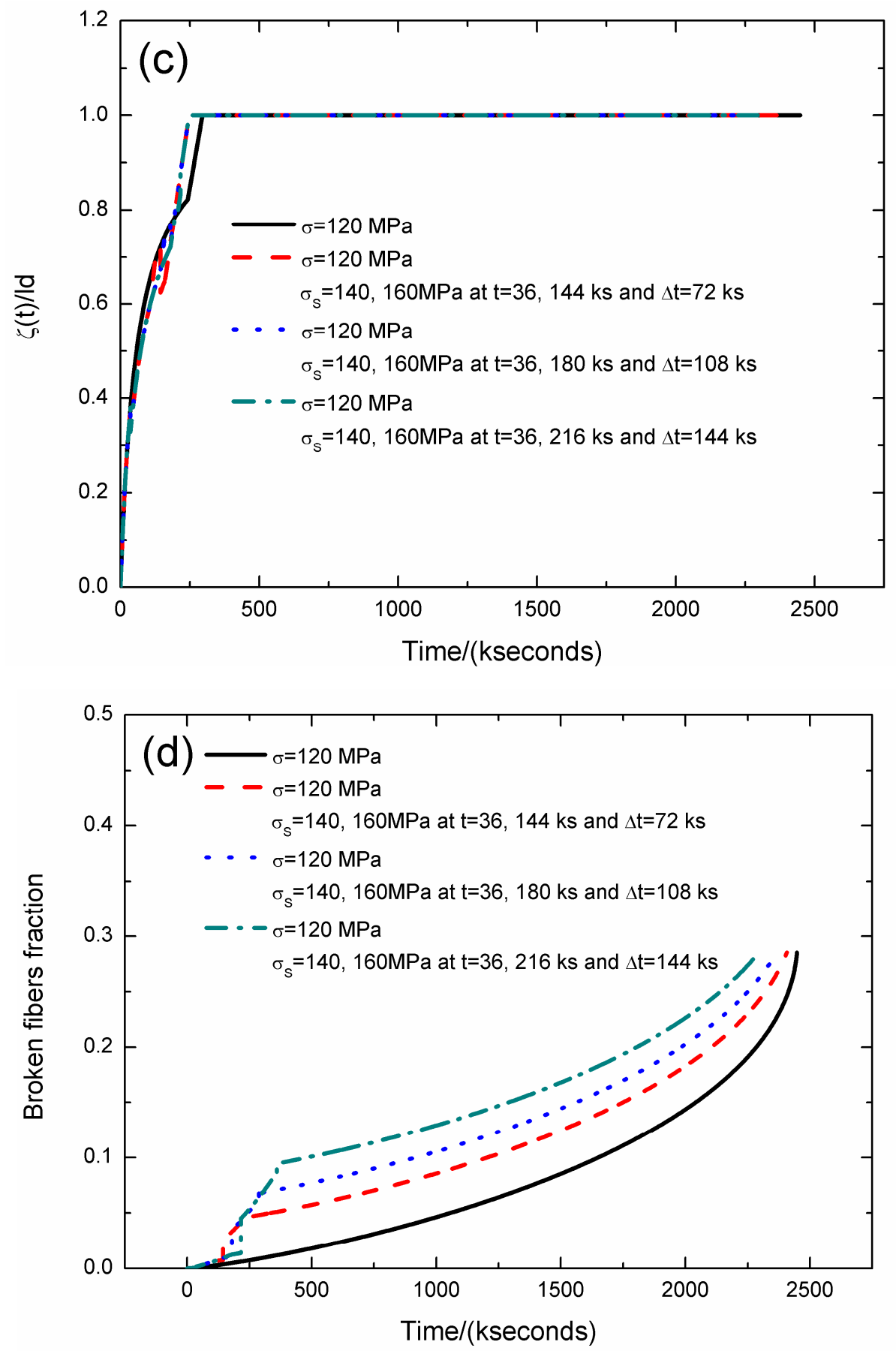

Figure 8. (a) The strain versus the time curves; (b) the fiber/matrix interface debonding length versus the time curves; (c) the fiber/matrix interface oxidation length versus the time curves; and (d) the broken fibers fraction versus the time curves of $\mathrm{SiC} / \mathrm{SiC}$ composite under stress-rupture loading of constant stress of $\sigma=120 \mathrm{MPa}, \sigma_{\mathrm{S}}=140 / 160 \mathrm{MPa}$ at $t=36 / 144,36 / 180,36 / 216 \mathrm{kseconds}$ and $\Delta \mathrm{t}=72,108,144$ kseconds at $800^{\circ} \mathrm{C}$ in air atmosphere. 
Table 6. The strain, fiber/matrix interface debonding and oxidation length, and broken fibers fraction of $\mathrm{SiC} / \mathrm{SiC}$ composite under stress-rupture loading of constant stress of $\sigma=120 \mathrm{MPa}, \sigma_{\mathrm{S}}=140 / 160 \mathrm{MPa}$ at $t=36 / 144,36 / 180,36 / 216$ kseconds and $\Delta \mathrm{t}=72,108,144 \mathrm{kseconds}$ at $800{ }^{\circ} \mathrm{C}$ in air atmosphere.

\begin{tabular}{|c|c|c|c|c|c|c|c|c|c|c|c|}
\hline$\sigma / \mathbf{M P a}$ & 120 & 120 & 120 & 120 & 120 & & & & & & \\
\hline$t / \mathrm{kseconds}$ & 0 & 36 & 242.7 & 295.3 & 2447.9 & & & & & & \\
\hline$\varepsilon_{\mathrm{c}} / \%$ & 0.053 & 0.07 & 0.163 & 0.17 & 0.201 & & & & & & \\
\hline $2 l_{\mathrm{d}} / l_{\mathrm{c}}$ & 0.203 & 0.322 & 1.0 & 1.0 & 1.0 & & & & & & \\
\hline$\zeta / l_{\mathrm{d}}$ & 0 & 0.380 & 0.822 & 1.0 & 1.0 & & & & & & \\
\hline$P$ & $1 \times 10^{-6}$ & $6.5 \times 10^{-4}$ & 0.007 & 0.009 & 0.285 & & & & & & \\
\hline$\sigma / \mathrm{MPa}$ & 120 & 120 & 140 & 140 & 120 & 120 & 160 & 160 & 120 & 120 & 120 \\
\hline$t /$ kseconds & 0 & 36 & 36 & 108 & 108 & 144 & 144 & 216 & 216 & 246.8 & 2407.2 \\
\hline$\varepsilon_{\mathrm{C}} / \%$ & 0.053 & 0.07 & 0.093 & 0.138 & 0.114 & 0.132 & 0.198 & 0.231 & 0.168 & 0.171 & 0.197 \\
\hline $2 l_{\mathrm{d}} / l_{\mathrm{c}}$ & 0.203 & 0.322 & 0.423 & 0.694 & 0.694 & 0.77 & 0.936 & 1.0 & 1.0 & 1.0 & 1.0 \\
\hline$\zeta / l_{\mathrm{d}}$ & 0 & 0.380 & 0.328 & 0.601 & 0.601 & 0.72 & 0.624 & 0.876 & 0.876 & 1.0 & 1.0 \\
\hline$P$ & $1 \times 10^{-6}$ & $6.5 \times 10^{-4}$ & 0.0016 & 0.0065 & 0.0065 & 0.007 & 0.025 & 0.041 & 0.045 & 0.046 & 0.285 \\
\hline$\sigma / \mathrm{MPa}$ & 120 & 120 & 140 & 140 & 120 & 120 & 160 & 160 & 120 & 120 & \\
\hline$t /$ kseconds & 0 & 36 & 36 & 144 & 144 & 180 & 180 & 288 & 288 & 2365.7 & \\
\hline$\varepsilon_{\mathrm{c}} / \%$ & 0.053 & 0.07 & $0 . .093$ & 0.16 & 0.133 & 0.15 & 0.219 & 0.237 & 0.171 & 0.194 & \\
\hline $2 l_{\mathrm{d}} / l_{\mathrm{c}}$ & 0.203 & 0.322 & 0.423 & 0.829 & 0.829 & 0.904 & 1.0 & 1.0 & 1.0 & 1.0 & \\
\hline$\zeta / l_{\mathrm{d}}$ & 0 & 0.380 & 0.328 & 0.671 & 0.671 & 0.768 & 0.73 & 1.0 & 1.0 & 1.0 & \\
\hline$P$ & $1 \times 10^{-6}$ & $6.5 \times 10^{-4}$ & 0.0016 & 0.009 & 0.009 & 0.01 & 0.035 & 0.062 & 0.067 & 0.285 & \\
\hline$\sigma / \mathrm{MPa}$ & 120 & 120 & 140 & 140 & 120 & 120 & 160 & 160 & 120 & 120 & \\
\hline$t /$ kseconds & 0 & 36 & 36 & 180 & 180 & 216 & 216 & 360 & 360 & 2294.8 & \\
\hline$\varepsilon_{\mathrm{C}} / \%$ & 0.053 & 0.07 & 0.093 & 0.182 & 0.152 & 0.166 & 0.231 & 0.24 & 0.172 & 0.192 & \\
\hline $2 l_{\mathrm{d}} / l_{\mathrm{c}}$ & 0.203 & 0.322 & 0.423 & 0.964 & 0.964 & 1.0 & 1.0 & 1.0 & 1.0 & 1.0 & \\
\hline$\zeta / l_{\mathrm{d}}$ & 0 & 0.380 & 0.328 & 0.72 & 0.72 & 0.833 & 0.876 & 1.0 & 1.0 & 1.0 & \\
\hline$P$ & $1 \times 10^{-6}$ & $6.5 \times 10^{-4}$ & 0.0016 & 0.012 & 0.012 & 0.013 & 0.045 & 0.086 & 0.094 & 0.285 & \\
\hline
\end{tabular}

When the stochastic loading time spacing is $\Delta t=72$ kseconds, the stress-rupture lifetime is $t=2407.2 \mathrm{kseconds}$; the time for the interface complete debonding is $t=160 \mathrm{kseconds}$ at stochastic stress of $\sigma_{\mathrm{S}}=160 \mathrm{MPa}$; the time for the interface complete oxidation is $t=246.8 \mathrm{kseconds}$ at constant stress of $\sigma=120 \mathrm{MPa}$; the failure strain is $\varepsilon_{\mathrm{c}}=0.197 \%$; and the broken fibers fraction is $P=0.285$. When the stochastic loading time spacing is $\Delta t=144 \mathrm{kseconds}$, the stress-rupture lifetime is $t=2294.8$ kseconds; the time for the interface complete debonding is $t=205.7 \mathrm{kseconds}$ at constant stress of $\sigma=120 \mathrm{MPa}$; the time for the interface complete oxidation is $t=246.8 \mathrm{kseconds}$ at stochastic stress of $\sigma_{\mathrm{S}}=160 \mathrm{MPa}$; the failure strain is $\varepsilon_{\mathrm{c}}=0.192 \%$; and the broken fibers fraction is $P=0.285$.

\subsection{Case IV}

For the stochastic loading of Case IV, the strain, fiber/matrix interface debonding and oxidation length, and the broken fibers fraction of $\mathrm{SiC} / \mathrm{SiC}$ composite under stress-rupture loading of constant stress of $\sigma=120 \mathrm{MPa}, \sigma_{\mathrm{S}}=130 / 140 / 150,140 / 150 / 160,150 / 160 / 170 \mathrm{MPa}$ at $t=36 / 108 / 180 \mathrm{kseconds}$ and $\Delta t=36 \mathrm{kseconds}$ at $800{ }^{\circ} \mathrm{C}$ in air atmosphere are shown in Figure 9 and Table 7 . When the stochastic loading stress increases, the stress-rupture lifetime decreases, and the time for the interface complete oxidation decreases.

When the stochastic loading stress is $\sigma_{\mathrm{S}}=130,140,150 \mathrm{MPa}$, the stress-rupture lifetime is $t=2416.2$ kseconds; the time for the interface complete debonding is $t=180 \mathrm{kseconds}$ at stochastic loading stress of $\sigma_{\mathrm{S}}=150 \mathrm{MPa}$; the time for the interface complete oxidation is $t=251.3 \mathrm{kseconds}$ at constant stress of $\sigma=120 \mathrm{MPa}$; the failure strain is $\varepsilon_{\mathrm{C}}=0.198 \%$; and the broken fibers fraction is $P=0.285$. When the stochastic loading stress is $\sigma_{\mathrm{S}}=140,150,160 \mathrm{MPa}$, the stress-rupture lifetime is $t=2357.2 \mathrm{kseconds}$; the time for the interface complete debonding is $t=180 \mathrm{kseconds}$ at stochastic loading stress of $\sigma_{\mathrm{S}}=160 \mathrm{MPa}$; the time for the interface complete oxidation is $t=246.8 \mathrm{kseconds}$ at constant stress of $\sigma=120 \mathrm{MPa}$; the failure strain is $\varepsilon_{\mathrm{C}}=0.194 \%$; and the broken fibers fraction is $P=0.285$. When the stochastic loading stress is $\sigma_{\mathrm{S}}=150,160,170 \mathrm{MPa}$, the stress-rupture lifetime is $t=2209.1 \mathrm{kseconds}$; the time for the interface complete debonding is $t=180 \mathrm{kseconds}$ at stochastic loading stress of $\sigma_{\mathrm{S}}=170 \mathrm{MPa}$; the time for the interface complete oxidation is $t=244.4$ kseconds 
at constant stress of $\sigma=120 \mathrm{MPa}$; the failure strain is $\varepsilon_{\mathrm{C}}=0.189 \%$; and the broken fibers fraction is $P=0.285$.

Table 7. The strain, fiber/matrix interface debonding and oxidation length, and broken fibers fraction of $\mathrm{SiC} / \mathrm{SiC}$ composite under stress-rupture loading of constant stress of $\sigma=120 \mathrm{MPa}, \sigma_{\mathrm{S}}=130 / 140 / 150$, $140 / 150 / 160,150 / 160 / 170 \mathrm{MPa}$ at $t=36 / 108 / 180 \mathrm{kseconds}$ and $\Delta \mathrm{t}=36 \mathrm{kseconds}$ at $800^{\circ} \mathrm{C}$ in air atmosphere.

\begin{tabular}{|c|c|c|c|c|c|c|c|c|c|c|c|c|c|c|c|}
\hline$\sigma / \mathrm{MPa}$ & 120 & 120 & 120 & 120 & 120 & & & & & & & & & & \\
\hline$t /$ kseconds & 0 & 36 & 242.7 & 295.3 & 2447.9 & & & & & & & & & & \\
\hline$\varepsilon_{c} / \%$ & 0.053 & 0.07 & 0.163 & 0.17 & 0.201 & & & & & & & & & & \\
\hline $2 l_{\mathrm{d}} / l_{\mathrm{c}}$ & 0.203 & 0.322 & 1.0 & 1.0 & 1.0 & & & & & & & & & & \\
\hline$\zeta / l_{\mathrm{d}}$ & 0 & 0.380 & 0.822 & 1.0 & 1.0 & & & & & & & & & & \\
\hline$P$ & $1 \times 10^{-6}$ & $6.5 \times 10^{-4}$ & 0.007 & 0.009 & 0.285 & & & & & & & & & & \\
\hline$\sigma / \mathrm{MPa}$ & 120 & 120 & 130 & 130 & 120 & 120 & 140 & 140 & 120 & 120 & 150 & 150 & 120 & 120 & 120 \\
\hline$t /$ kseconds & 0 & 36 & 36 & 72 & 72 & 108 & 108 & 144 & 144 & 180 & 180 & 216 & 216 & 251.3 & 2416.2 \\
\hline$\varepsilon_{\mathrm{c}} / \%$ & 0.053 & 0.07 & 0.081 & 0.101 & 0.092 & 0.109 & 0.138 & 0.16 & 0.133 & 0.15 & 0.2 & 0.214 & 0.167 & 0.171 & 0.198 \\
\hline $2 l_{\mathrm{d}} / l_{\mathrm{c}}$ & 0.203 & 0.322 & 0.375 & 0.503 & 0.503 & 0.604 & 0.694 & 0.829 & 0.829 & 0.904 & 1.0 & 1.0 & 1.0 & 1.0 & 1.0 \\
\hline$\zeta / l_{\mathrm{d}}$ & 0 & 0.380 & 0.352 & 0.525 & 0.525 & 0.656 & 0.602 & 0.671 & 0.671 & 0.768 & 0.717 & 0.86 & 0.86 & 1.0 & 1.0 \\
\hline$P$ & $1 \times 10^{-6}$ & $6.5 \times 10^{-4}$ & 0.001 & 0.0025 & 0.0025 & 0.003 & 0.0075 & 0.0104 & 0.0113 & 0.012 & 0.027 & 0.03 & 0.04 & 0.041 & 0.285 \\
\hline$\sigma / \mathrm{MPa}$ & 120 & 120 & 140 & 140 & 120 & 120 & 150 & 150 & 120 & 120 & 160 & 160 & 120 & 120 & 120 \\
\hline$t /$ kseconds & 0 & 36 & 36 & 72 & 72 & 108 & 108 & 144 & 144 & 180 & 180 & 216 & 216 & 246.8 & 2357.2 \\
\hline$\varepsilon_{\mathrm{c}} / \%$ & 0.053 & 0.07 & 0.093 & 0.115 & 0.096 & 0.113 & 0.154 & 0.179 & 0.137 & 0.154 & 0.22 & 0.231 & 0.168 & 0.171 & 0.194 \\
\hline $2 l_{\mathrm{d}} / l_{\mathrm{c}}$ & 0.203 & 0.322 & 0.423 & 0.558 & 0.558 & 0.635 & 0.747 & 0.887 & 0.887 & 0.933 & 1.0 & 1.0 & 1.0 & 1.0 & 1.0 \\
\hline$\zeta / l_{\mathrm{d}}$ & 0 & 0.380 & 0.328 & 0.498 & 0.498 & 0.656 & 0.576 & 0.647 & 0.647 & 0.768 & 0.73 & 0.876 & 0.876 & 1.0 & 1.0 \\
\hline$P$ & $1 \times 10^{-6}$ & $6.5 \times 10^{-4}$ & 0.0016 & 0.0039 & 0.0039 & 0.005 & 0.0123 & 0.0168 & 0.0192 & 0.02 & 0.044 & 0.053 & 0.068 & 0.069 & 0.285 \\
\hline$\sigma / \mathrm{MPa}$ & 120 & 120 & 150 & 150 & 120 & 120 & 160 & 160 & 120 & 120 & 170 & 170 & 120 & 120 & 120 \\
\hline$t /$ kseconds & 0 & 36 & 36 & 72 & 72 & 108 & 108 & 144 & 144 & 180 & 180 & 216 & 216 & 244.4 & 2209.1 \\
\hline$\varepsilon_{\mathrm{c}} / \%$ & 0.053 & 0.07 & 0.104 & 0.129 & 0.098 & 0.116 & 0.17 & 0.198 & 0.138 & 0.156 & 0.237 & 0.25 & 0.169 & 0.171 & 0.189 \\
\hline $2 l_{\mathrm{d}} / l_{\mathrm{c}}$ & 0.203 & 0.322 & 0.467 & 0.607 & 0.607 & 0.656 & 0.792 & 0.936 & 0.936 & 0.95 & 1.0 & 1.0 & 1.0 & 1.0 & 1.0 \\
\hline$\zeta / l_{\mathrm{d}}$ & 0 & 0.380 & 0.308 & 0.473 & 0.473 & 0.656 & 0.553 & 0.624 & 0.224 & 0.768 & 0.737 & 0.884 & 0.884 & 1.0 & 1.0 \\
\hline$P$ & $1 \times 10^{-6}$ & $6.5 \times 10^{-4}$ & 0.0024 & 0.0059 & 0.0059 & 0.007 & 0.019 & 0.026 & 0.0305 & 0.03 & 0.07 & 0.083 & 0.11 & 0.11 & 0.285 \\
\hline
\end{tabular}

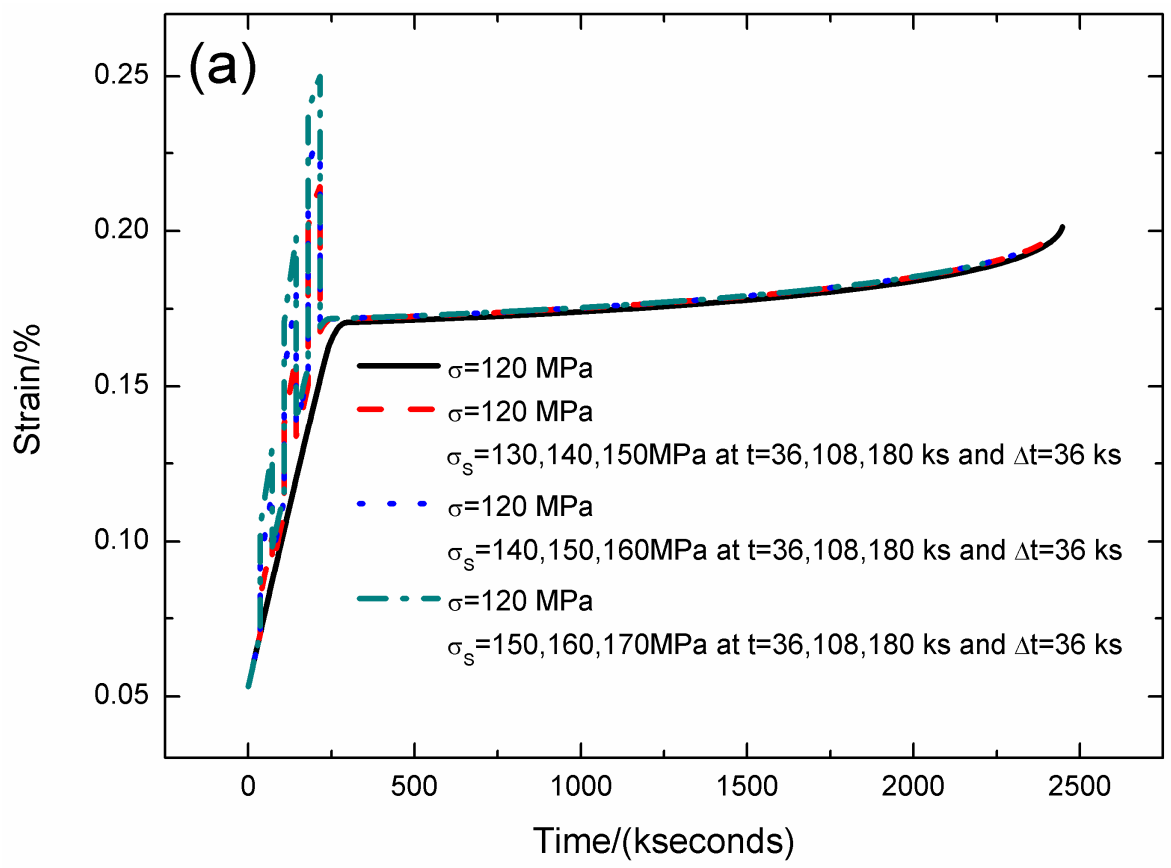

Figure 9. Cont. 

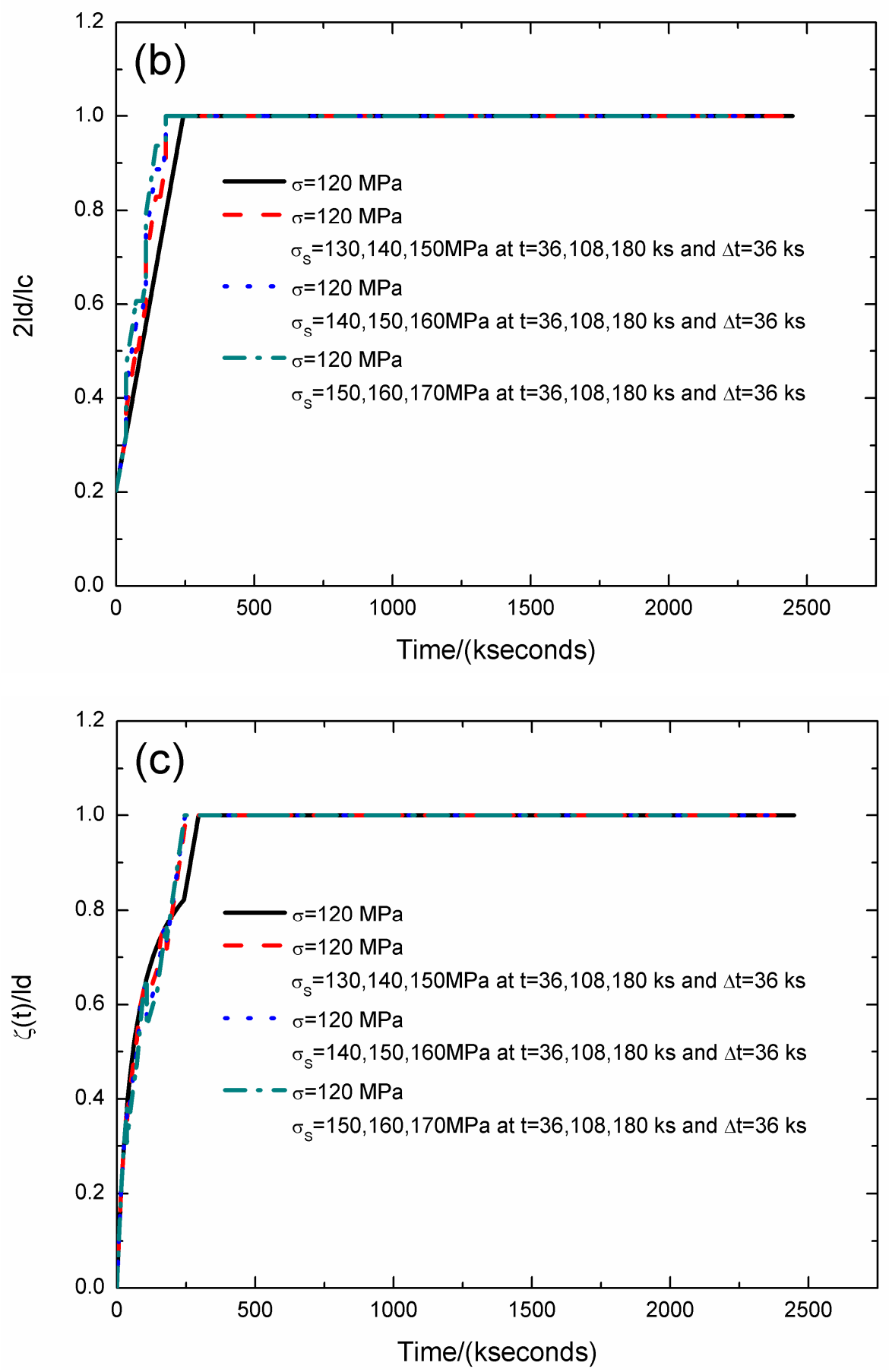

Figure 9. Cont. 


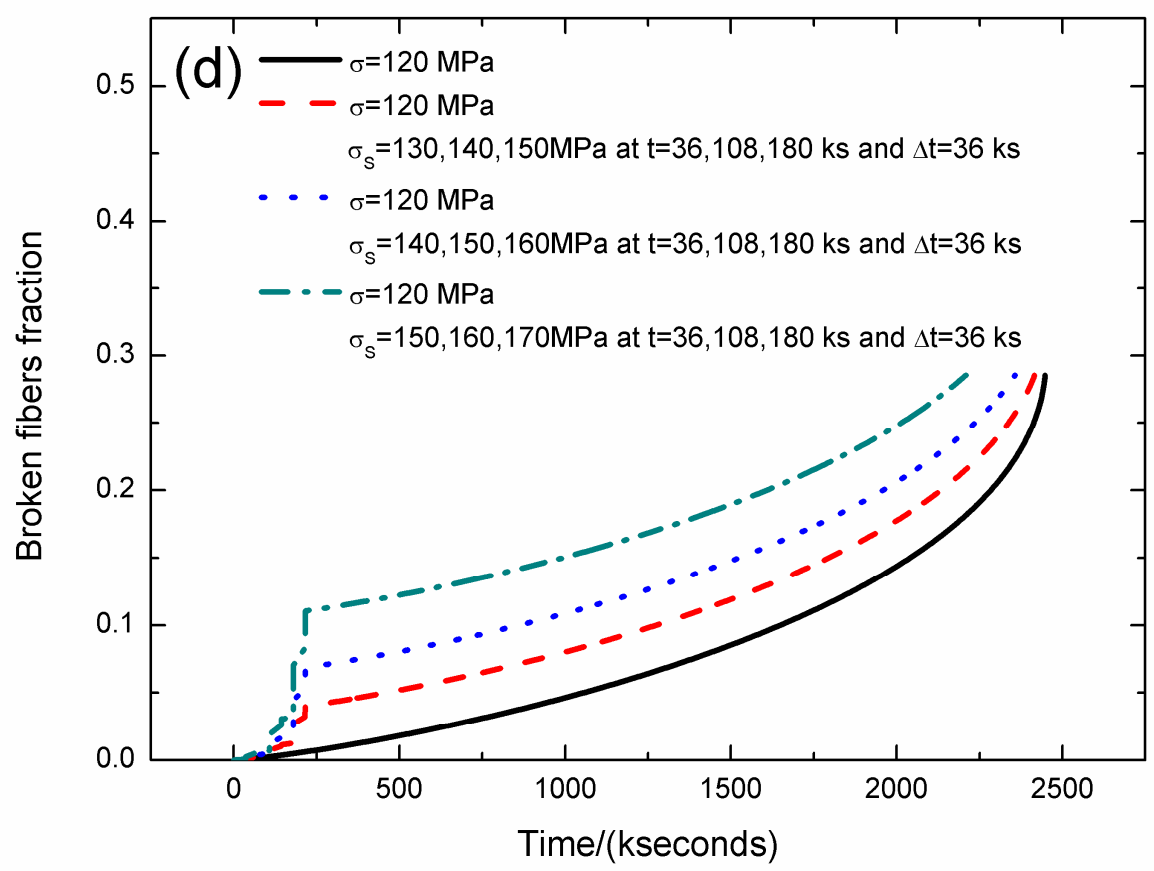

Figure 9. (a) The strain versus the time curves; (b) the fiber/matrix interface debonding length versus the time curves; (c) the fiber/matrix interface oxidation length versus the time curves; and (d) the broken fibers fraction versus the time curves of $\mathrm{SiC} / \mathrm{SiC}$ composite under stress-rupture loading of constant stress of $\sigma=120 \mathrm{MPa}, \sigma_{\mathrm{S}}=130 / 140 / 150,140 / 150 / 160,150 / 160 / 170 \mathrm{MPa}$ at $t=36 / 108 / 180 \mathrm{kseconds}$ and $\Delta t=36$ kseconds at $800{ }^{\circ} \mathrm{C}$ in air atmosphere.

The strain, fiber/matrix interface debonding and oxidation length, and the broken fibers fraction of $\mathrm{SiC} / \mathrm{SiC}$ composite under stress-rupture loading of constant stress of $\sigma=120 \mathrm{MPa}, \sigma_{\mathrm{S}}=140 / 160 / 180 \mathrm{MPa}$ at $t=72 / 144 / 216,108 / 180 / 252,144 / 216 / 288 \mathrm{kseconds}$ and $\Delta t=36 \mathrm{kseconds}$ at $800{ }^{\circ} \mathrm{C}$ in air atmosphere are shown in Figure 10 and Table 8 . When the stochastic loading time increases, the stress-rupture lifetime decreases, and the time for the interface complete debonding and oxidation increases.

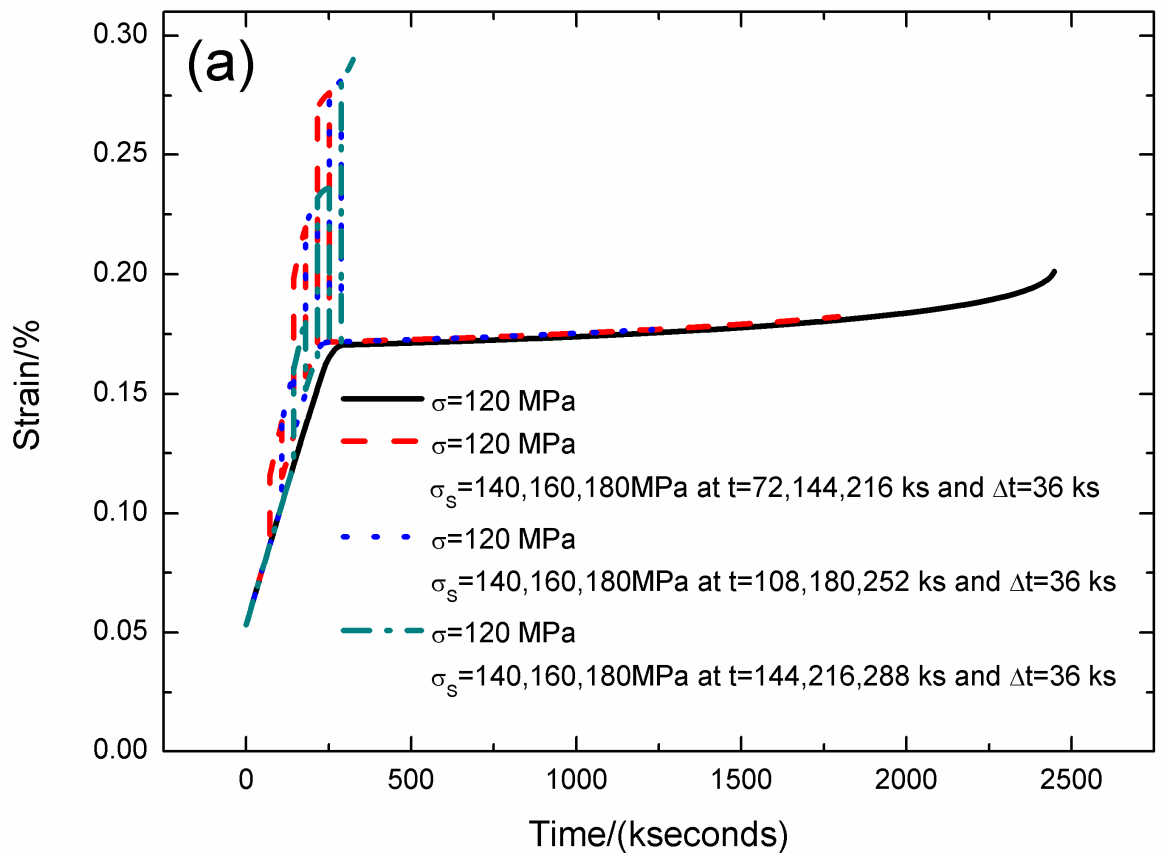

Figure 10. Cont. 

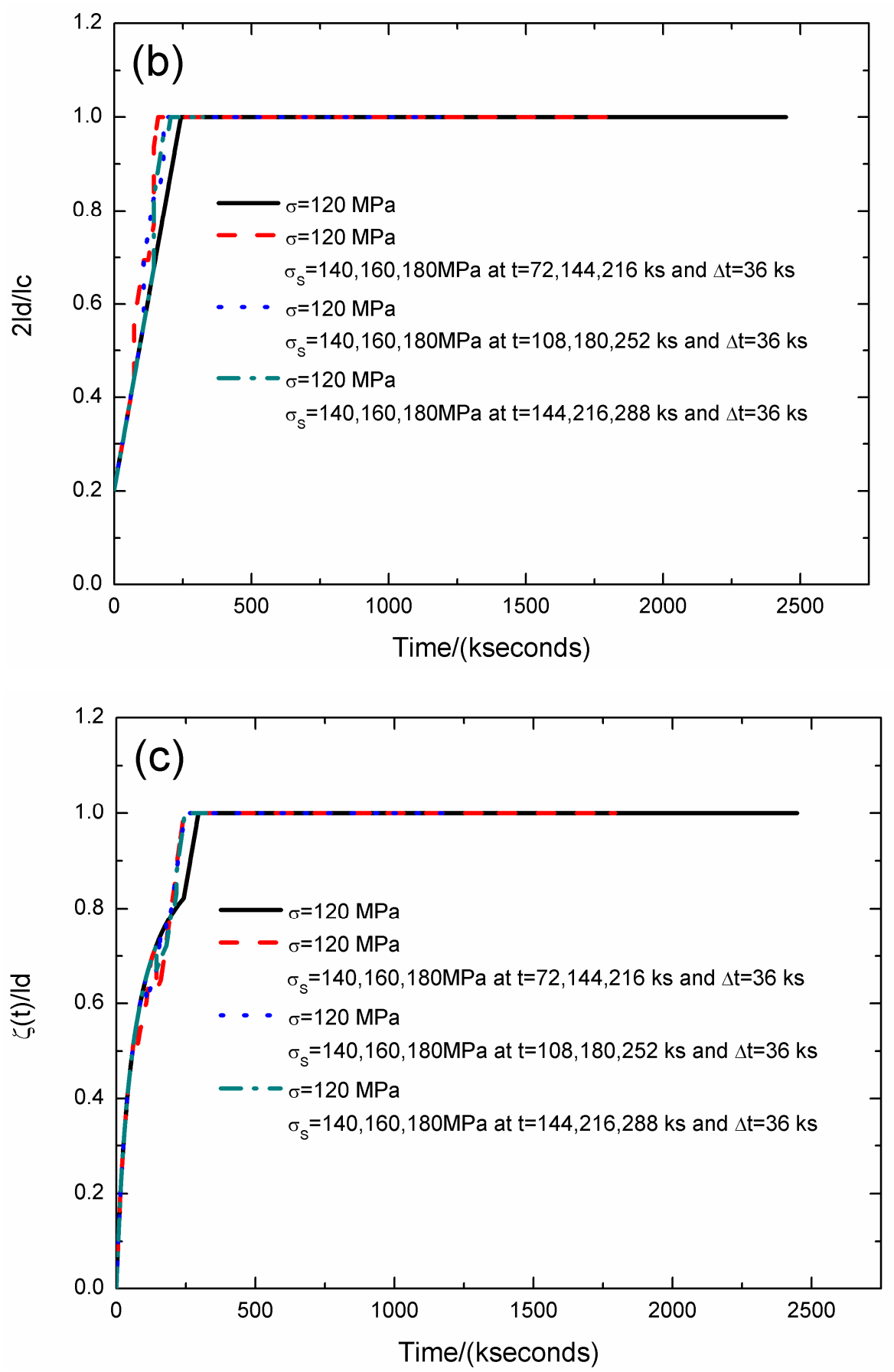

Figure 10. Cont. 


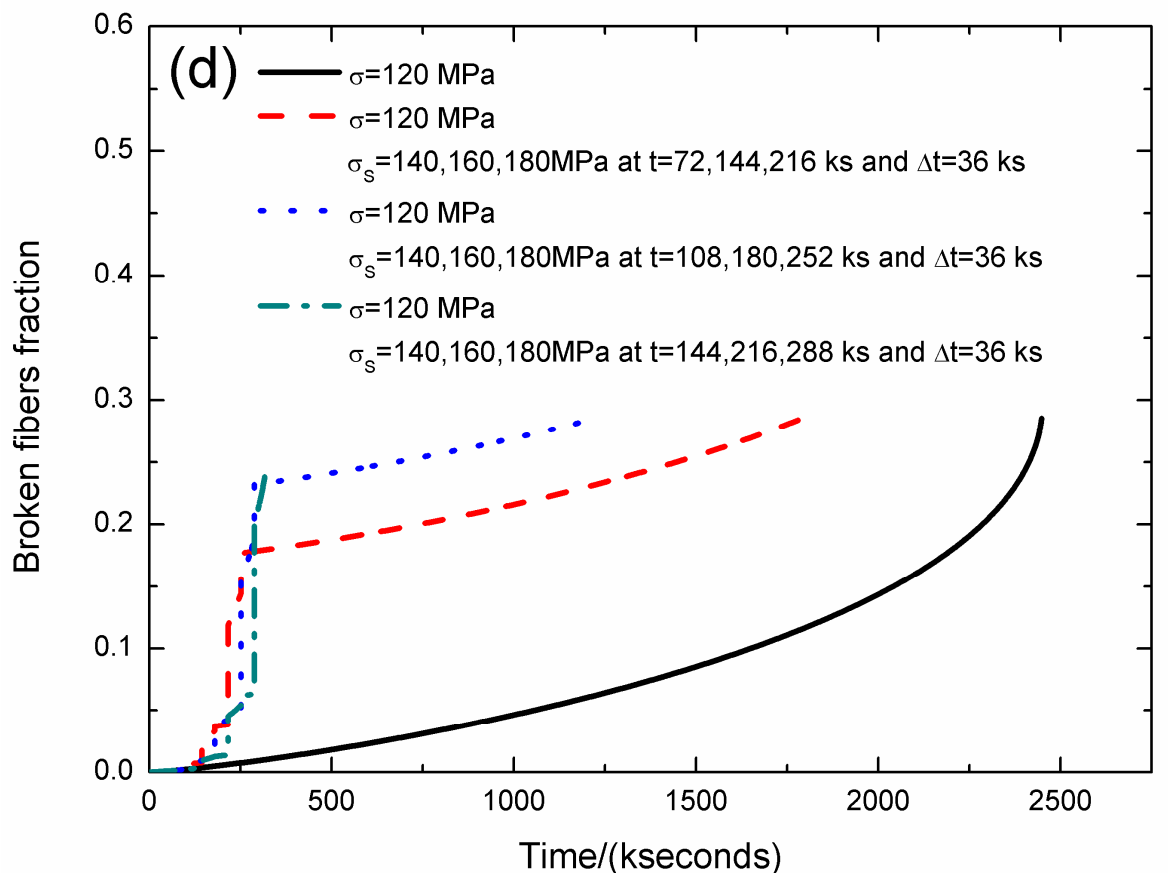

Figure 10. (a) The strain versus the time curves; (b) the fiber/matrix interface debonding length versus the time curves; (c) the fiber/matrix interface oxidation length versus the time curves; and (d) the broken fibers fraction versus the time curves of $\mathrm{SiC} / \mathrm{SiC}$ composite under stress-rupture loading of constant stress of $\sigma=120 \mathrm{MPa}, \sigma_{\mathrm{S}}=140 / 160 / 180 \mathrm{MPa}$ at $t=72 / 144 / 216 \mathrm{kseconds}$ and $\Delta \mathrm{t}=36 \mathrm{kseconds}$ at $800{ }^{\circ} \mathrm{C}$ in air atmosphere.

Table 8. The strain, fiber/matrix interface debonding and oxidation length, and broken fibers fraction of $\mathrm{SiC} / \mathrm{SiC}$ composite under stress-rupture loading of constant stress of $\sigma=120 \mathrm{MPa}, \sigma_{\mathrm{S}}=140 / 160 / 180 \mathrm{MPa}$ at $t=72 / 144 / 216,108 / 180 / 252,144 / 216 / 288$ kseconds and $\Delta \mathrm{t}=36 \mathrm{kseconds}$ at $800{ }^{\circ} \mathrm{C}$ in air atmosphere.

\begin{tabular}{|c|c|c|c|c|c|c|c|c|c|c|c|c|c|c|}
\hline$\sigma / \mathrm{MPa}$ & 120 & 120 & 120 & 120 & 120 & & & & & & & & & \\
\hline$t /$ kseconds & 0 & 36 & 242.7 & 295.3 & 2447.9 & & & & & & & & & \\
\hline$\varepsilon_{\mathrm{c}} / \%$ & 0.053 & 0.07 & 0.163 & 0.17 & 0.201 & & & & & & & & & \\
\hline $2 l_{\mathrm{d}} / l_{\mathrm{c}}$ & 0.203 & 0.322 & 1.0 & 1.0 & 1.0 & & & & & & & & & \\
\hline$\zeta / l_{\mathrm{d}}$ & 0 & 0.380 & 0.822 & 1.0 & 1.0 & & & & & & & & & \\
\hline$P$ & $1 \times 10^{-6}$ & $6.5 \times 10^{-4}$ & 0.007 & 0.009 & 0.285 & & & & & & & & & \\
\hline$\sigma / \mathrm{MPa}$ & 120 & 120 & 140 & 140 & 120 & 120 & 160 & 160 & 120 & 120 & 180 & 180 & 120 & 120 \\
\hline$t /$ kseconds & 0 & 72 & 72 & 108 & 108 & 144 & 144 & 180 & 180 & 216 & 216 & 252 & 252 & 1794 \\
\hline$\varepsilon_{\mathrm{c}} / \%$ & 0.053 & 0.087 & 0.115 & 0.138 & 0.115 & 0.132 & 0.198 & 0.22 & 0.157 & 0.168 & 0.269 & 0.276 & 0.171 & 0.182 \\
\hline $2 l_{\mathrm{d}} / l_{\mathrm{c}}$ & 0.203 & 0.44 & 0.558 & 0.694 & 0.694 & 0.77 & 0.936 & 1.0 & 1.0 & 1.0 & 1.0 & 1.0 & 1.0 & 1.0 \\
\hline$\zeta / l_{\mathrm{d}}$ & 0 & 0.555 & 0.498 & 0.601 & 0.601 & 0.722 & 0.624 & 0.73 & 0.73 & 0.876 & 0.888 & 1.0 & 1.0 & 1.0 \\
\hline$P$ & $1 \times 10^{-6}$ & 0.0015 & 0.0039 & 0.0065 & 0.0065 & 0.0076 & 0.025 & 0.033 & 0.037 & 0.038 & 0.118 & 0.144 & 0.177 & 0.285 \\
\hline$\sigma / \mathrm{MPa}$ & 120 & 120 & 140 & 140 & 120 & 120 & 160 & 160 & 120 & 120 & 180 & 180 & 120 & 120 \\
\hline$t /$ kseconds & 0 & 108 & 108 & 144 & 144 & 180 & 180 & 216 & 216 & 252 & 252 & 288 & 288 & 1230.8 \\
\hline$\varepsilon_{\mathrm{c}} / \%$ & 0.053 & 0.103 & 0.138 & 0.16 & 0.133 & 0.15 & 0.22 & 0.232 & 0.168 & 0.171 & 0.276 & 0.281 & 0.172 & 0.177 \\
\hline $2 l_{\mathrm{d}} / l_{\mathrm{c}}$ & 0.203 & 0.558 & 0.694 & 0.829 & 0.829 & 0.904 & 1.0 & 1.0 & 1.0 & 1.0 & 1.0 & 1.0 & 1.0 & 1.0 \\
\hline$\zeta / l_{\mathrm{d}}$ & 0 & 0.656 & 0.601 & 0.671 & 0.671 & 0.768 & 0.73 & 0.876 & 0.876 & 1.0 & 1.0 & 1.0 & 1.0 & 1.0 \\
\hline$P$ & $1 \times 10^{-6}$ & 0.0025 & 0.0065 & 0.0094 & 0.0094 & 0.01 & 0.034 & 0.043 & 0.048 & 0.05 & 0.155 & 0.189 & 0.231 & 0.285 \\
\hline$\sigma / \mathrm{MPa}$ & 120 & 120 & 140 & 140 & 120 & 120 & 160 & 160 & 120 & 120 & 180 & 180 & & \\
\hline$t /$ kseconds & 0 & 144 & 144 & 180 & 180 & 216 & 216 & 252 & 252 & 288 & 288 & 324 & & \\
\hline$\varepsilon_{\mathrm{C}} / \%$ & 0.053 & 0.12 & 0.16 & 0.182 & 0.152 & 0.165 & 0.231 & 0.236 & 0.171 & 0.172 & 0.282 & 0.29 & & \\
\hline $2 l_{\mathrm{d}} / l_{\mathrm{c}}$ & 0.203 & 0.677 & 0.829 & 0.964 & 0.964 & 1.0 & 1.0 & 1.0 & 1.0 & 1.0 & 1.0 & 1.0 & & \\
\hline$\zeta / l_{\mathrm{d}}$ & 0 & 0.722 & 0.671 & 0.72 & 0.72 & 0.833 & 0.876 & 1.0 & 1.0 & 1.0 & 1.0 & 1.0 & & \\
\hline$P$ & $1 \times 10^{-6}$ & 0.0037 & 0.0094 & 0.012 & 0.012 & 0.013 & 0.045 & 0.054 & 0.061 & 0.063 & 0.2 & 0.25 & & \\
\hline
\end{tabular}

When the stochastic loading time is $t=72,144,216$ kseconds, the stress-rupture lifetime is $t=1794$ kseconds; the time for the interface complete debonding is $t=160 \mathrm{kseconds}$ at stochastic loading stress of $\sigma_{\mathrm{S}}=160 \mathrm{MPa}$; the time for the interface complete oxidation is $t=243.3 \mathrm{kseconds}$ at stochastic loading stress of $\sigma_{\mathrm{S}}=180 \mathrm{MPa}$; the failure strain is $\varepsilon_{\mathrm{C}}=0.182 \%$; and the broken fibers fraction is $P=0.285$. When the stochastic loading time is $t=144,216,288 \mathrm{kseconds}$, the stress-rupture lifetime is $t=324$ kseconds; the time for the interface complete debonding is $t=205.7$ kseconds at constant 
stress of $\sigma=120 \mathrm{MPa}$; the time for the interface complete oxidation is $t=246.8 \mathrm{kseconds}$ at stochastic loading stress of $\sigma_{\mathrm{S}}=160 \mathrm{MPa}$; the failure strain is $\varepsilon_{\mathrm{C}}=0.29 \%$; and the broken fibers fraction is $P=0.25$.

The strain, fiber/matrix interface debonding and oxidation length, and the broken fibers fraction of $\mathrm{SiC} / \mathrm{SiC}$ composite under stress-rupture loading of constant stress of $\sigma=120 \mathrm{MPa}, \sigma_{\mathrm{S}}=140 / 160 / 180$ $\mathrm{MPa}$ at $t=36 / 144 / 216,36 / 180 / 324,36 / 216 / 360 \mathrm{kseconds}$ and $\Delta t=72,108,144 \mathrm{kseconds}$ at $800{ }^{\circ} \mathrm{C}$ in air atmosphere are shown in Figure 11 and Table 9. When the stochastic loading time spacing increases, the stress-rupture lifetime decreases, and the time for the interface complete debonding increases.
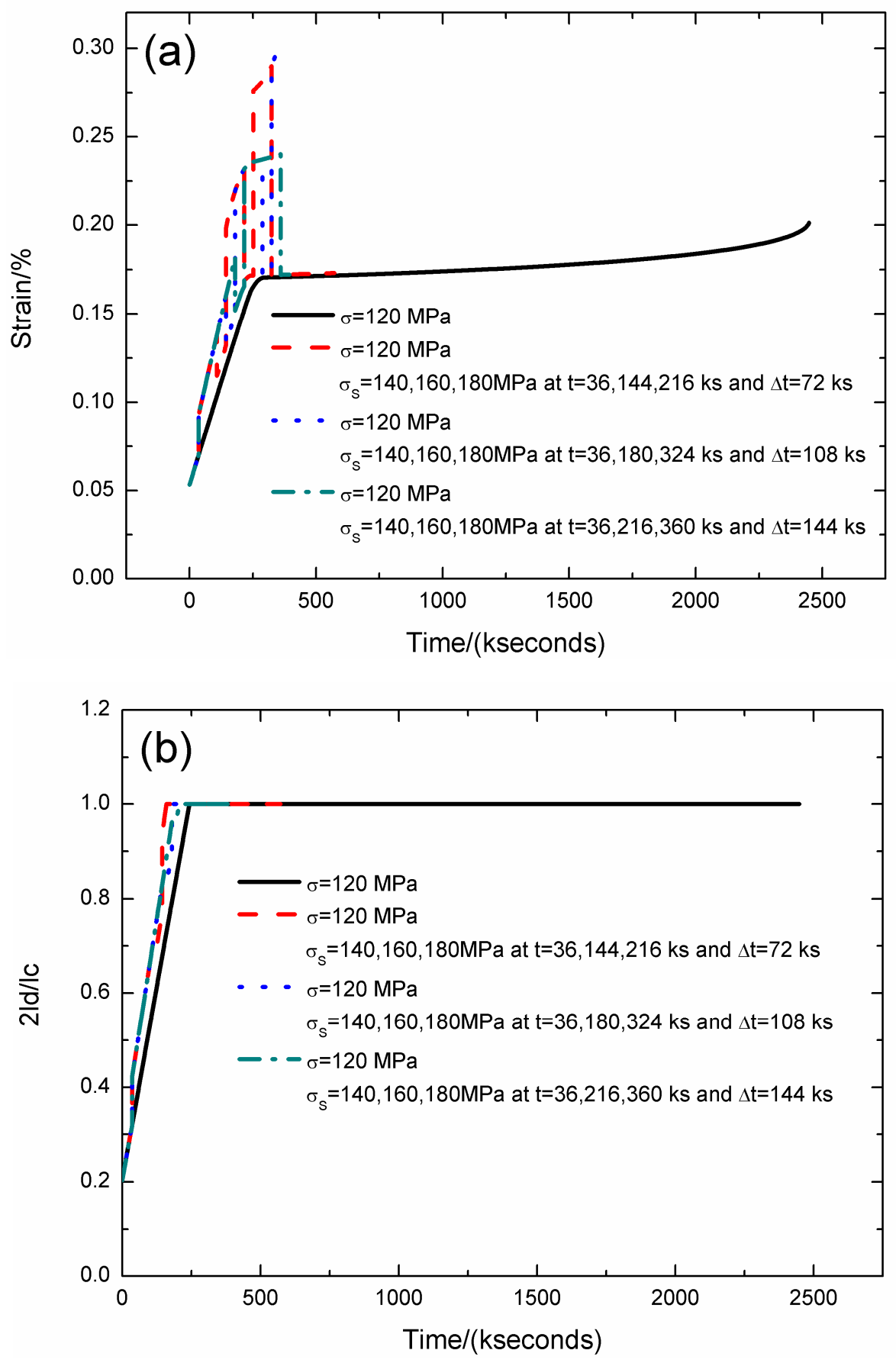

Figure 11. Cont. 

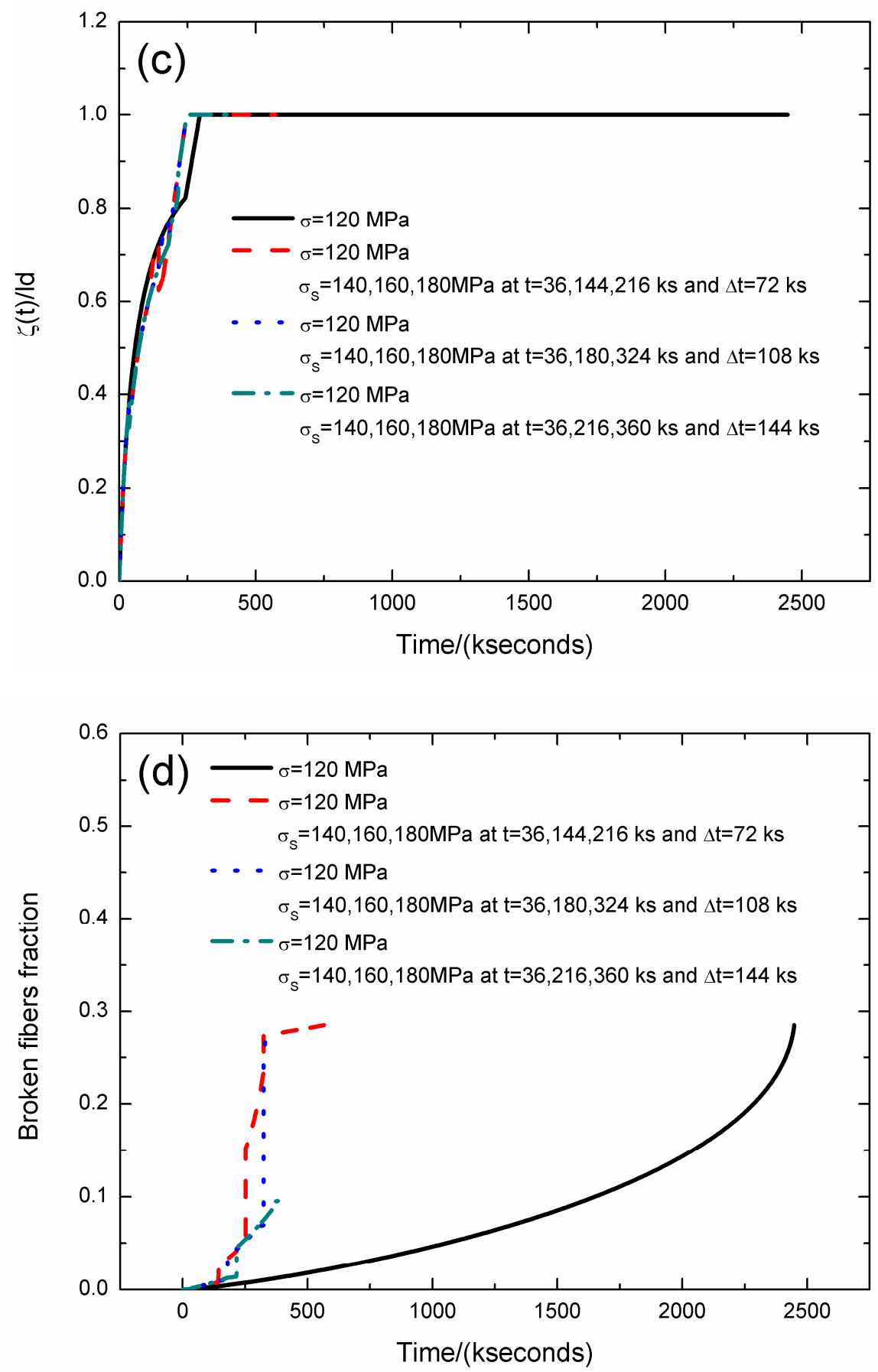

Figure 11. (a) The strain versus the time curves; (b) the fiber/matrix interface debonding length versus the time curves; (c) the fiber/matrix interface oxidation length versus the time curves; and (d) the broken fibers fraction versus the time curves of $\mathrm{SiC} / \mathrm{SiC}$ composite under stress-rupture loading of constant stress of $\sigma=120 \mathrm{MPa}, \sigma_{\mathrm{S}}=140 / 160 / 180 \mathrm{MPa}$ at $t=36 / 144 / 216,36 / 180 / 324,36 / 216 / 360 \mathrm{kseconds}$ and $\Delta \mathrm{t}=72,108,144 \mathrm{kseconds}$ at $800^{\circ} \mathrm{C}$ in air atmosphere. 
Table 9. The strain, fiber/matrix interface debonding and oxidation length, and broken fibers fraction of $\mathrm{SiC} / \mathrm{SiC}$ composite under stress-rupture loading of constant stress of $\sigma=120 \mathrm{MPa}, \sigma_{\mathrm{S}}=140 / 160 / 180$ $\mathrm{MPa}$ at $t=36 / 144 / 216,36 / 180 / 324,36 / 216 / 360$ kseconds and $\Delta \mathrm{t}=72,108,144$ kseconds at $800{ }^{\circ} \mathrm{C}$ in air atmosphere.

\begin{tabular}{|c|c|c|c|c|c|c|c|c|c|c|c|c|c|c|}
\hline$\sigma / \mathrm{MPa}$ & 120 & 120 & 120 & 120 & 120 & & & & & & & & & \\
\hline$t / \mathrm{kseconds}$ & 0 & 36 & 242.7 & 295.3 & 2447.9 & & & & & & & & & \\
\hline$\varepsilon_{\mathrm{c}} / \%$ & 0.053 & 0.07 & 0.163 & 0.17 & 0.201 & & & & & & & & & \\
\hline $2 l_{\mathrm{d}} / l_{\mathrm{c}}$ & 0.203 & 0.322 & 1.0 & 1.0 & 1.0 & & & & & & & & & \\
\hline$\zeta / l_{\mathrm{d}}$ & 0 & 0.380 & 0.822 & 1.0 & 1.0 & & & & & & & & & \\
\hline$P$ & $1 \times 10^{-6}$ & $6.5 \times 10^{-4}$ & 0.007 & 0.009 & 0.285 & & & & & & & & & \\
\hline$\sigma / \mathrm{MPa}$ & 120 & 120 & 140 & 140 & 120 & 120 & 160 & 160 & 120 & 120 & 180 & 180 & 120 & 120 \\
\hline$t /$ kseconds & 0 & 36 & 36 & 108 & 108 & 144 & 144 & 216 & 216 & 252 & 252 & 324 & 324 & 572.4 \\
\hline$\varepsilon_{\mathrm{C}} / \%$ & 0.053 & 0.07 & 0.093 & 0.138 & 0.115 & 0.132 & 0.198 & 0.231 & 0.168 & 0.171 & 0.267 & 0.29 & 0.172 & 0.173 \\
\hline $2 l_{\mathrm{d}} / l_{\mathrm{c}}$ & 0.203 & 0.322 & 0.423 & 0.694 & 0.694 & 0.77 & 0.936 & 1.0 & 1.0 & 1.0 & 1.0 & 1.0 & 1.0 & 1.0 \\
\hline$\zeta / l_{\mathrm{d}}$ & 0 & 0.380 & 0.328 & 0.601 & 0.601 & 0.722 & 0.624 & 0.876 & 0.876 & 1.0 & 1.0 & 1.0 & 1.0 & 1.0 \\
\hline$P$ & $1 \times 10^{-6}$ & $6.5 \times 10^{-4}$ & 0.0016 & 0.0065 & 0.0065 & 0.007 & 0.025 & 0.041 & 0.045 & 0.046 & 0.151 & 0.235 & 0.274 & 0.285 \\
\hline$\sigma / \mathrm{MPa}$ & 120 & 120 & 140 & 140 & 120 & 120 & 160 & 160 & 120 & 120 & 180 & 180 & & \\
\hline$t /$ kseconds & 0 & 36 & 36 & 144 & 144 & 180 & 180 & 288 & 288 & 324 & 324 & 337.8 & & \\
\hline$\varepsilon_{\mathrm{c}} / \%$ & 0.053 & 0.07 & 0.093 & 0.16 & 0.133 & 0.15 & 0.22 & 0.237 & 0.171 & 0.172 & 0.29 & 0.295 & & \\
\hline $2 l_{\mathrm{d}} / l_{\mathrm{c}}$ & 0.203 & 0.322 & 0.423 & 0.829 & 0.829 & 0.904 & 1.0 & 1.0 & 1.0 & 1.0 & 1.0 & 1.0 & & \\
\hline$\zeta / l_{\mathrm{d}}$ & 0 & 0.380 & 0.328 & 0.671 & 0.671 & 0.768 & 0.73 & 1.0 & 1.0 & 1.0 & 1.0 & 1.0 & & \\
\hline$P$ & $1 \times 10^{-6}$ & $6.5 \times 10^{-4}$ & 0.0016 & 0.009 & 0.009 & 0.01 & 0.035 & 0.062 & 0.067 & 0.069 & 0.254 & 0.285 & & \\
\hline$\sigma / \mathrm{MPa}$ & 120 & 120 & 140 & 140 & 120 & 120 & 160 & 160 & 120 & 120 & 180 & & & \\
\hline$t / \mathrm{kseconds}$ & 0 & 36 & 36 & 180 & 180 & 216 & 216 & 360 & 360 & 396 & 396 & & & \\
\hline$\varepsilon_{\mathrm{c}} / \%$ & 0.053 & 0.07 & 0.093 & 0.182 & 0.152 & 0.165 & 0.231 & 0.24 & 0.172 & 0.172 & & & & \\
\hline $2 l_{\mathrm{d}} / l_{\mathrm{c}}$ & 0.203 & 0.322 & 0.423 & 0.964 & 0.964 & 1.0 & 1.0 & 1.0 & 1.0 & 1.0 & - & & & \\
\hline$\zeta / l_{\mathrm{d}}$ & 0 & 0.380 & 0.328 & 0.72 & 0.72 & 0.833 & 0.876 & 1.0 & 1.0 & 1.0 & - & & & \\
\hline$P$ & $1 \times 10^{-6}$ & $6.5 \times 10^{-4}$ & 0.0016 & 0.012 & 0.012 & 0.013 & 0.045 & 0.086 & 0.094 & 0.096 & - & & & \\
\hline
\end{tabular}

When the stochastic loading time spacing is $\Delta t=72 \mathrm{kseconds}$, the stress-rupture lifetime is $t=572.4$ kseconds; the time for the interface complete debonding is $t=160 \mathrm{kseconds}$ at stochastic loading stress of $\sigma_{\mathrm{S}}=160 \mathrm{MPa}$; the time for the interface complete oxidation is $t=246.8 \mathrm{kseconds}$ at constant stress of $\sigma=120 \mathrm{MPa}$; the failure strain is $\varepsilon_{\mathrm{C}}=0.173 \%$; and the broken fibers fraction is $P=0.285$. When the stochastic loading time spacing is $\Delta t=144 \mathrm{kseconds}$, the stress-rupture lifetime is $t=396 \mathrm{kseconds}$; the time for the interface complete debonding is $t=205.7 \mathrm{kseconds}$ at constant stress of $\sigma=120 \mathrm{MPa}$; the time for the interface complete oxidation is $t=246.8 \mathrm{kseconds}$ at stochastic loading stress of $\sigma_{\mathrm{S}}=160 \mathrm{MPa}$.

\section{Conclusions}

In this paper, the damage evolution and lifetime of fiber-reinforced CMCs under stress-rupture with stochastic loading at intermediate temperatures were investigated. The relationships between the stochastic loading stress level, time, time spacing, damage mechanisms of matrix cracking, interface debonding and oxidation, and fiber failure were established. The strain, fiber/matrix interface debonding and oxidation length, and the broken fibers fraction versus the time curves of $\mathrm{SiC} / \mathrm{SiC}$ composite under constant stress and three different stochastic loading conditions were analyzed. The effects of the stochastic loading stress level, stochastic loading time, and time spacing on the damage evolution and lifetime of $\mathrm{SiC} / \mathrm{SiC}$ composite were discussed. For the stochastic loading of Cases II, III, and IV, the stress-rupture lifetime decreases with increasing stochastic loading stress level, time, and time spacing. The time for the interface complete debonding and oxidation is affected by the loading mode, stress level, loading time, and time spacing.

Funding: This research was funded by the Fundamental Research Funds for the Central Universities grant number [NS2019038].

Acknowledgments: The author also wishes to thank three anonymous reviewers and editors for their helpful comments on an earlier version of the paper.

Conflicts of Interest: The authors declare no conflicts of interest. 


\section{References}

1. Naslain, R. Design, Preparation and properties of non-oxide CMCs for application in engines and nuclear reactors: An overview. Compos. Sci. Technol. 2004, 64, 155-170. [CrossRef]

2. DiCarlo, J.A.; Roode, M. Ceramic Composite Development for Gas Turbine Hot Section Components; ASME paper GT2006-90151: Barcelona, Spain, 8-11 May 2006.

3. Li, L. Damage, Fracture and Fatigue of Ceramic-Matrix Composites; Springer Nature Singapore Pte Ltd., 2018; ISBN 978-981-13-1782-8. Available online: https://www.springer.com/in/book/9789811317828 (accessed on 1 September 2018).

4. Li, L. Thermomechanical Fatigue of Ceramic-Matrix Composites; Wiley-VCH: Berlin, Germany, 2019; ISBN 978-3-527-34637-0. [CrossRef]

5. Recle, E.; Godin, N.; Reynaud, P.; Fantozzi, G. Fatigue lifetime of ceramic matrix composites at intermediate temperature by acoustic emission. Materials 2017, 10, 658. [CrossRef] [PubMed]

6. Ruggles-Wrenn, M.B.; Christensen, D.T.; Chamberlain, A.L.; Lane, J.E.; Cook, T.S. Effect of frequency and environment on fatigue behavior of a CVI SiC/SiC ceramic matrix composite at $1200^{\circ} \mathrm{C}$. Compos. Sci. Technol. 2011, 71, 190-196. [CrossRef]

7. Dassios, K.G.; Aggelis, D.G.; Kordatos, E.Z.; Matikas, T.E. Cyclic loading of a SiC-fiber reinforced ceramic matrix composite reveals damage mechanisms and thermal residual stress state. Compos. Part A 2013, 44, 105-113. [CrossRef]

8. Rebillat, F. Advances in self-healing ceramic matrix composites. In Advances in Ceramic Matrix Composites; Low, I.M., Ed.; Woodhead Publishing: Cambridge, UK, 2014; ISBN 978-0-85709-120-8.

9. Lara-Curzio, E. Stress rupture of Nicalon/SiC continuous fiber ceramic composites in air at $950{ }^{\circ} \mathrm{C}$. J. Am. Ceram. Soc. 1997, 80, 3268-3272. [CrossRef]

10. Morscher, G.N. Tensile stress rupture of $\mathrm{SiC}_{\mathrm{f}} / \mathrm{SiC}_{\mathrm{m}}$ minicomposites with carbon and boron nitride interphases at elevated temperatures in air. J. Am. Ceram. Soc. 1997, 80, 2029-2042. [CrossRef]

11. Verrilli, M.J.; Opila, E.J.; Calomino, A.; Kiser, J.D. Effect of environment on the stress-rupture behavior of a carbon-fiber-reinforced silicon carbide ceramic matrix composites. J. Am. Ceram. Soc. 2004, 87, 1536-1542. [CrossRef]

12. Hussain, A.; Calabria-Holley, J.; Lawrence, M.; Jiang, Y. Hygrothermal and mechanical characterization of novel hemp shiv based thermal insulation composites. Constr. Build. Mater. 2019, 212, 561-568. [CrossRef]

13. Khosravani, M.R.; Weihberg, K. Experimental investigations of the environmental effects on stability and integrity of composite sandwich T-joints. Mater. Werkst. 2017, 48, 753-759. [CrossRef]

14. Morscher, G.N.; Hurst, J.; Brewer, D. Intermediate-temperature stress rupture of a woven Hi-Nicalon, BN-interphase, SiC-matrix composite in air. J. Am. Ceram. Soc. 2000, 83, 1441-1449. [CrossRef]

15. Morscher, G.N.; Cawley, J.D. Intermediate temperature strength degradation in SiC/SiC composites. J. Eur. Ceram. Soc. 2002, 22, 2777-2787. [CrossRef]

16. Li, L. Damage evolution of cross-ply ceramic-matrix composites under stress-rupture and cyclic loading at elevated temperatures in oxidizing atmosphere. Mater. Sci. Eng. A 2017, 688, 315-321.

17. Li, L. Synergistic effects of temperature, oxidation, loading frequency and stress-rupture on damage evolution of cross-ply ceramic matrix composites under cyclic fatigue loading at elevated temperatures in oxidizing atmosphere. Eng. Fract. Mech. 2017, 175, 15-30. [CrossRef]

18. Momon, S.; Moevus, M.; Godin, N.; R’Mili, M.; Reynaud, P.; Fantozzi, G.; Fayolle, G. Acoustic emission and lifetime prediction during static fatigue tests on ceramic-matrix-composite at high temperature under air. Compos. Part A 2010, 41, 913-918. [CrossRef]

19. Godin, N.; Reynaud, P.; Fantozzi, G. Contribution of AE analysis in order to evaluate time to failure of ceramic matrix composites. Eng. Fract. Mech. 2019, 210, 452-469. [CrossRef]

20. Ikarashi, T.; Ogasawara, T.; Aoki, T. Effects of cyclic tensile loading on rupture behavior of orthogonal 3-D woven $\mathrm{SiC}$ fiber/SiC matrix composites at elevated temperatures in air. J. Eur. Ceram. Soc. 2019, 39, 806-812. [CrossRef]

21. Casas, L.; Martinez-Esnaola, J.M. Modeling the effect of oxidation on the creep behavior of fiber-reinforced ceramic matrix composites. Acta Mater. 2003, 51, 3745-3757. [CrossRef]

22. Curtin, W.A. Multiple matrix cracking in brittle matrix composites. Acta Metal. Mater. 1993, 41, $1369-1377$. [CrossRef] 
23. Gao, Y.; Mai, Y.; Cotterell, B. Fracture of fiber-reinforced materials. J. Appl. Math. Phys. 1988, 39, 550-572. [CrossRef]

24. Curtin, W.A. Theory of mechanical properties of ceramic-matrix composites. J. Am. Ceram. Soc. 1991, 74, 2837-2845. [CrossRef]

25. Lara-Curzio, E. Analysis of oxidation-assisted stress-rupture of continuous fiber-reinforced ceramic matrix composites at intermediate temperatures. Compos. Part A 1999, 30, 549-554. [CrossRef] 